\title{
Towards a general theory of social and economic development: Evolution of coordination mechanisms ${ }^{\text {th }}$
}

\author{
Victor Polterovich ${ }^{\mathrm{a}, \mathrm{b}, *}$ \\ ${ }^{a}$ Central Economics and Mathematics Institute, Russian Academy of Sciences, Moscow, Russia \\ ${ }^{\mathrm{b}}$ Moscow School of Economics, Lomonosov Moscow State University, Moscow, Russia
}

\begin{abstract}
A new approach to understanding social and economic development is proposed, based on consideration of the evolution of coordination mechanisms. The work consists of two parts. In the first part, a critical analysis of four recently proposed theories of social development, focusing on geographical, institutional or cultural factors, is given. These theories have greatly enriched our understanding of the evolution of society, however, as analysis shows, none of them provides a satisfactory description of the driving forces and mechanisms of this evolution; the main reason is rooted in their common deficiency-monocausality. It is proposed to distinguish between two types of development, catching up and leading. The basic ideas of the theory of catching up development are presented. This approach makes it possible to explain the phenomenon of the "economic miracle" as a result of mutually conditioned changes in culture, institutions, technological progress and well-being in the context of interaction of competition, power and collaboration mechanisms.
\end{abstract}

The second part is devoted to the theory of leading socioeconomic development. It is shown how in Western Europe, as a result of the interaction of the above four factors, specific forms and combinations of the three main mechanisms of coordination - competition, power and collaboration - emerged at each stage of evolution. I emphasize the importance of ideology and the phenomenon of technical progress in the formation of institutions of economic and political competition that contributed to the creation of the welfare state. These changes and economic growth created the conditions for further transformation of civil culture: increasing levels of trust, tolerance, altruism and cosmopolitanism, expanding the planning horizon. The decrease in the level of coercion built into the mechanisms of power and competition

\footnotetext{
The updated English version of the article published in Russian in Voprosy Ekonomiki, 2018, No. 11, pp. 5-26 (Part 1); No. 12, pp. 77-102 (Part 2).

* E-mail address: polterov@mail.ru
}

(C) 2018 Non-profit partnership "Voprosy Ekonomiki". This is an open access article distributed under the terms of the Attribution-NonCommercial-NoDerivatives 4.0 (CC BY-NC-ND 4.0). 
are demonstrated as well as the expansion of the role of collaboration. A hypothesis is advanced that the speed of this process depends on geographical factors. The idea of the welfare world is discussed.

Keywords: inclusive institutions, extractive institutions, limited access order, open access order, cycle of emancipation, violence, rent, power, competition, collaboration, industrial revolution, welfare state, civic culture.

JEL classification: B4, B52, D7, H1, N4, O14, P5, P11.

\section{Part 1. Geography, institutions, or culture?}

\subsection{Introduction}

During the past 20 years, a new trend has become evident in the enhancement of economic knowledge - and possibly in social sciences as a whole - namely an increase in the number of inter- and multidisciplinary researches and the publication of some works claiming the elaboration of a general theory of socioeconomic development. This trend was reflected to the greatest extent in the four theories proposed by Diamond (1997), North, Wallis and Weingast (2009), Acemoglu and Robinson (2012) and Welzel (2013). All these theories are based on the results of related disciplines, however, the first and the fourth oppose each other and the other two. Diamond insists on the primacy of geographic factors, North, Wallis and Weingast - as well as Acemoglu and Robinson - favor a purely institutional approach, whereas Welzel attempts to show that it is civic culture, rather than institutions, that plays a crucial role in socioeconomic development.

All four theories became widely known and gave rise to intense discussion. Acemoglu and Robinson's denial of the importance of geographic and cultural factors resulted in an especially heated debate; critics also pointed out numerous inaccuracies and controversies in their work (Diamond, 2012a, 2012b; Fukuyama, 2012; Arslanov, 2016). On the other hand, some authors, while noting the imperfections of the theory of inclusive and extractive institutions, consider it to be a major advancement in the theory of socioeconomic development (Zaostrovtsev, 2014; Natkhov and Polishchuk, 2017a, 2017b; Balatsky, 2017). Balatsky and Pliskevich (2017) tried to refine the theory to make it applicable to conditions in Russia.

According to Zaostrovtsev (2013, p. 141), giving up the "basic postulates of the economic mainstream," led North, Wallis and Weingast to suggest a "fundamentally different methodology for studying social dynamics, surpassing everything that modern economic development theories can offer". Zaostrovtsev's article refers to a number of other works which discuss the North-Wallis-Weingast theory.

The discussion between those asserting the primacy of institutional and geographic factors in explaining economic growth (though with no connection to Diamond's theory) is described in Kirdina (2016).

Welzel directly argues with institutional theorists, asserting that it is civic culture, rather than institutions, that is the dominant factor in socioeconomic development. He supports this statement with econometric calculations. 
This article consists of two parts. Part one compares the four aforementioned works in order to identify the difficulties arising with the corresponding approaches and outlines the ways to overcome them. Our analysis shows that, despite the undisputed importance of the theories under review, neither of them provides a satisfactory description of the driving forces and mechanisms for social development. The main reason is rooted in their common deficiency, i.e. monocausality, the attempt to explain the rise of modern Western societies based only on a single development factor: geography, institutions or civic culture. ${ }^{1}$ The authors admit, in one form or another, that they have reached the limit of explanatory power. Furthermore, in their recent article, Acemoglu and Robinson (2016) tried to offset this deficiency by introducing informal norms into consideration. However, as will be shown below, this turns out to be insufficient.

This main deficiency in the discussed theories is connected with two others. First, it still remains unexplained why clearly imperfect institutions and civic cultures were dominant in societies for thousands of years. Second, modern Western democracies are presented as a kind of "the end of history": no attempts have been made to reveal tendencies of their future development.

Acemoglu and Robinson cite two examples which they believe demonstrate the primacy of institutions over civic culture: the history of the two Koreas and the city of Nogales, belonging partly to the U.S.A. and partly to Mexico. As shown below, these examples represent two very specific development scenarios: repressive evolution and the integration of a region into a more developed environment. In both cases, the introduction of institutions inadequate for the state of civic culture is caused by political factors. In the first scenario, we are dealing with the forceful deterioration in the quality of institutions and, in the second, their improvement is achieved through external support that is normally lacking in standard situations. Thus, the statement regarding the domination of institutions over the cultural development factor remains unconvincing.

In order to overcome the deficiency of the aforementioned theories, this paper suggests distinguishing between two types of development - catching up and leading - and viewing socioeconomic evolution in the context of the mutual influence of the three basic mechanisms of interaction between individuals and organizations: competition, power and collaboration. Part one describes the main ideas of the four theories and provides their critical analysis. Further, we state the main ideas of the suggested theory of the first type, relying on the concept of catching up development institutions (Polterovich, 2016a, 2016b) and explaining the "economic miracle" phenomenon as a result of interrelated changes in culture, institutions, technical progress and the level of well-being.

Part two of the paper is dedicated to the theory of leading socioeconomic development; here we are in fact dealing with the evolution of Western societies. We will show how specific forms and combinations of the three basic coordination mechanisms appeared under the influence of the above four factors at every stage of evolution. We stress the significance of ideology and the phenomenon of technical progress in shaping the institutions of economic and political competi-

\footnotetext{
1 Which is all the more surprising, knowing that the authors of institutional theories, North and Acemoglu, stressed the importance of culture in their other papers. In particular, North has written more than once about the relevance of ideology as a factor for social change (see, e.g. North, 1990).
} 
tion which, in turn, stimulated the development of an ideology of social progress and the development of the welfare state. These changes, along with economic growth, created the conditions for further transforming civic culture: increasing the levels of trust, tolerance, altruism and cosmopolitanism and extending the planning horizon. We demonstrate a decreasing level of coercion built into the mechanisms of power and competition and an expanding role of collaboration. We put forward a hypothesis that the speed of these processes depends on geographical factors. In conclusion, we discuss the idea of the welfare world.

Our approach relies mainly on the consideration of the processes which took place in Western countries starting in the $14^{\text {th }}$ century and does not pretend to provide a detailed explanation for the events which happened in any particular state. We study only the "turning points" of evolution, omitting the development issues of the ancient world. It should be noted, however, that the proposed concept emphasizes the relevance of answering a question that has been posed more than once by researchers: "Why was the ideology of technical progress neglected by the elites of ancient states, and why were innovations often rejected by the rulers?"

\subsection{Why is Eurasia ahead of other continents: the role of geographic factors}

It should be noted that Diamond, an advocate of the dominating role of geographic factors, sets out a narrower task for himself than other authors. He attempts to explain why Eurasia (which the author deems to include North Africa, due to their close ties) outstripped other continents in development and gave birth to modern civilization. In this context, he identified Eurasia's four advantages over other continents.

1. Out of the 14 species of domestic animals existing today, 13 species originated from ancestors that only inhabited Eurasia. South America was the only habitat for the predecessor of the llama and alpaca, whereas in North America, Australia and sub-Sahara Africa, there were no animals fit for domestication. Eurasia was also richer in farmable plants than other continents. This is why Eurasia has considerably surpassed the other continents in the development of agriculture and, accordingly, in the transition from nomadic to sedentary life.

Due to developing agriculture, Europeans acquired immunity to the germs carried by domestic animals. Following the discovery of America, millions of its natives died from epidemics that arose from contact with the Europeans. Diamond believes this factor contributed to the success of the conquerors even more than their firearms.

2. Eurasia is aligned from east to west, rather than north to south like America and Africa. The less significant regional climatic differences facilitated the spread of new agricultural technologies and housekeeping methods. As Africa and especially America stretch along a north-south axis and are divided by geographic and environmental barriers, diffusion occurred at a much slower pace.

3. The diffusion between Eurasia and sub-Sahara Africa took place under relatively favorable conditions, while America and Australia were isolated from the other continents.

4. Eurasia was far ahead of other continents in terms of area and total population. This encouraged the emergence and spreading of innovations. 
Diamond's arguments appear convincing, but his theory fails to touch upon the driving forces and mechanisms behind the development of the Western civilization in modern and contemporary history.

\subsection{Causes of wealth and poverty: extractive and inclusive institutions}

According to the Acemoglu-Robinson (AR) theory, the economic success or failure of a system depends on whether extractive or inclusive institutions dominate in it.

Inclusive institutions "allow and encourage participation by the great mass of people in economic activities that make best use of their talents and skills and that enable individuals to make the choices they wish. To be inclusive, economic institutions must feature secure private property, an unbiased system of law, and a provision of public services that provides a level playing field in which people can exchange and contract; it also must permit the entry of new businesses and allow people to choose their careers" (Acemoglu and Robinson, 2012, pp. 74-75). "We call such institutions, which have opposite properties to those we call inclusive, extractive economic institutions - extractive because such institutions are designed to extract incomes and wealth from one subset of society to benefit a different subset" (Acemoglu and Robinson, 2012, p. 76).

Extractive institutions are so common in history because they can ensure a relatively high level of well-being for all citizens, while redistributing most of the income in favor of the elite, which is therefore interested in supporting those institutions. Growth under extractive institutions requires, first of all, that the state is politically centralized. When this is achieved, the government or the elite controlling it usually receives powerful incentives to invest in the economy and develop it on one's own or to create conditions for others to do so, since economic expansion increases the rent extracted by the elite through extractive institutions. To this end, the elite may even attempt to reproduce certain attributes of inclusive institutions and markets (Acemoglu and Robinson, 2012, p. 149).

"By their very nature, extractive institutions do not foster creative destruction and generate at best only a limited amount of technological progress. The growth they engender thus lasts for only so long" (Acemoglu and Robinson, 2012, p. 150). The authors cite a number of examples supporting this statement.

The Roman Emperor Vespasian (69-79 AD) rejected a method that greatly reduced the costs of lifting columns up the Capitoline Hill. Vespasian rewarded the inventor but said, "Just let me feed my people a little." In 1589, Englishman William Lee invented a stocking frame knitting machine and asked Queen Elizabeth I for a patent. Elizabeth refused, saying, "This would rob the people of their work." She was concerned that if part of her subjects lost their jobs, this would lead to instability which might threaten her power. The authors note that her reaction illustrates the main idea of the book: extractive institutions prevent the development of Schumpeterian competition and, accordingly, the implementation of innovations.

According to the AR theory, the differences amongst the trajectories of economic development followed by different countries resulted from the complex interrelation between institutional drift (gradual change of institutions) and 
accidental turning points. ${ }^{2}$ As an example of such a "point," the authors cited the plague epidemics of 1346, which led to a workforce shortage. This resulted in greater bargaining power for workers, their wages in Western Europe began to grow and an inclusive labor market emerged.

Inclusive institutions create a positive feedback loop: their strengthening results in a more efficient distribution of resources, technical innovations and greater activity by individuals, thereby encouraging the further improvement of these institutions. However, to the fundamental question, "What can be done to kick-start or perhaps just facilitate the process of empowerment and thus the development of inclusive political institutions?", the authors do not give an answer declaring: "The honest answer of course is that there is no recipe for building such institutions" (Acemoglu and Robinson, 2012, p. 460). "History, as we have seen, is littered with examples of reform movements that succumbed to the iron law of oligarchy and replaced one set of extractive institutions with even more pernicious ones" (Acemoglu and Robinson, 2012, p. 457). This happened in England in 1688, in France in 1789 and in Japan during the Meiji Restoration and in many other countries. "Nasser vowed to build a modern egalitarian society in Egypt, but this led only to Hosni Mubarak's corrupt regime.... Robert Mugabe was viewed by many as a freedom fighter ousting Ian Smith's racist and highly extractive Rhodesian regime. But Zimbabwe's institutions became no less extractive, and its economic performance has been even worse than before independence" (Acemoglu and Robinson, 2012, p. 458).

Nevertheless, the authors point out "some obvious factors that would make the process of empowerment more likely to get off the ground" (Acemoglu and Robinson, 2012, p. 460):

- the existence of a certain level of centralization of governmental authority, so that the success of public movements challenging the existing regime does not lead to immediate anarchy;

- the existence of deeply rooted political institutions ensuring a certain degree of pluralism;

- the existence of the institutions of civil society that could coordinate protests by the population, so that the opposition movement would be hard to suppress. I do not believe that this list answers the question about the mechanism for transitioning to inclusive institutions. In essence, this is a statement that, in order to facilitate the transition, it would be useful to have institutions featuring the inclusive property, at least to some extent.

The Acemoglu-Robinson theory is very similar to the theory of social orders by North-Wallis-Weingast (NWW), published slightly earlier, so that F. Fukuyama essentially says that the AR theory lacks originality (Fukuyama, 2012).

\subsection{The theory of social orders}

In the NWW theory, the role of extractive and inclusive institutions is played by institutional models of social organization called social orders. The authors differentiate between limited access orders (LAO) and open access orders $(\mathrm{OAO})$. They believe that resolving the problem of violence is the main line of

2 The concept greatly resembles the Hegelian theory of transition from quantity to quality. 
socioeconomic development: "This book lays out a set of concepts that show how societies have used the control of political, economic, religious, and educational activities to limit and contain violence over the last ten thousand years" (North et al., 2009, Preface, p. xi).

The limited access order is typical for so-called natural states. ${ }^{3}$ It is characterized by a political system not based on general agreement between citizens, by the existence of a relatively low number of organizations controlled mostly by the elite, and by the dominance of social relations organized through personal connections. Institutions in LAOs reflect a belief that not all people were created equal; correspondingly, social hierarchies and privilege systems take shape; laws are applied selectively; ownership rights are not protected (North et al., 2009 , p. 12). As a rule, LAO economies exhibit slow growth and are susceptible to shocks.

"From the viewpoint of modern open access societies, patron-client networks appear inherently corrupt. Everything is personal. Whom an individual knows and who they are matter more than what they do. Such an attitude toward natural states, seemingly justified from the viewpoint of an open access society, misses the role that personality, personal relationships, and patronage networks play in containing violence within a natural state: personal relationships and rentcreation provide the incentive systems that contain violence and allow collaboration in a natural state. The inherently personal nature of all relationships in a natural state expresses the fundamental logic underlying the limited access social order... Limited access identifies privileges, creates rents, and provides credibility to personal relationships throughout the society" (North et al., 2009, pp. 37-38).

The statements above are fundamentally important for the theory of social orders. This is accentuated in another work with a somewhat extended list of authors: "Our approach to rents differs significantly from the literature that emphasizes rentseeking... and directly-unproductive policies..." (North et al., 2013, p. 5).

The elites play a special role in LAOs. "The natural state reduces the problem of endemic violence through the formation of a dominant coalition whose members possess special privileges" (North et al., 2009, p. 18).

"In a natural state, each of the nonmilitary elites either controls or enjoys privileged access to a vital function like religion, production, community allocation of resources, justice, trade, or education. Because the positions, privileges, and rents of the individual elites in the dominant coalition depend on the limited entry enforced by the continued existence of the regime, all elites have incentives to support and help maintain the coalition" (North et al., 2009, pp. 19-20).

"Because elites know that violence will reduce their own rents, they have incentives not to fight. Furthermore, each elite understands that other elites face similar incentives. In this way, the political system of a natural state manipulates the economic system to produce rents that then secure political order" (North et al., 2009, p. 18). The authors stress that the elite is a partnership rather than a contract-based organization: interactions within it are based on arrangements aligned with incentives, rather than on a contract enforced by a third party.

\footnotetext{
The term is not defined in the paper. The context suggests that natural states are those whose institutional systems are limited access orders.
} 
"Among the most valuable sources of elite rents is the privilege of forming organizations that the state will support. By devising ways to support contractual organizations and then extending the privilege of forming those organizations to their members, the dominant coalition creates a way to generate and distribute rents within the coalition... The ability of elites to organize cooperative behavior under the aegis of the state enhances the elite return from society's productive resources - land, labor, capital, and organizations" (North et al., 2009, p. 20).

OAOs are characterized by impersonal social interactions, the supremacy of law, protection of ownership rights and no limitations on economic, political, religious or educational activities. Unlike LAOs, the creation of organizations for an indefinite term in OAOs requires no approval from the government, thereby shaping a strong and dynamic civil society. The state ensures social security, supports education and infrastructure. Economic and political competition is welldeveloped (North et al., 2009, pp. 12, 22, 114).

Control over violence in an OAO is ensured by the consolidation of law enforcement agencies and by their subordination to the political system, which includes a number of institutions and incentives limiting illegitimate violence; a party or political group only retains power if widely supported by the public. Open access guarantees that the government is changed if control over armed forces is abused (North et al., 2009, pp. 22, 170).

The authors found a total of 25 modern states with an OAO. Unlike a LAO, an economy under an OAO develops more sustainably. Individuals and organizations in an open access society also strive to earn rents, but impersonal economic and political competition (according to Schumpeter) results in their erosion (North et al., 2009, pp. xii, 23).

The authors propose a typology of natural states depending on their ability to support organizations. A fragile state has no such ability and the state itself is unstable. A basic state can support only state-owned organizations. A mature state is also able to support a wide range of elite organizations not directly under its control.

The transition from a fragile natural state to a basic state is considered using the examples of the Aztec (1430) and Carolingian (750) empires whose evolutions turned out to be similar in many respects. The history of France and England in the $16^{\text {th }}, 17^{\text {th }}$, and $18^{\text {th }}$ centuries is an illustration of the transition from a basic natural to a mature state.

When considering the issue of transition from LAO to OAO, the theory of social orders suggests distinguishing “... two development problems that are normally conflated... the second problem involves the transition of societies from limited access orders LAOs to OAOs, but the first challenge involves the development of LAO societies toward forms of social organization that enable more economic output, reduced violence, stable political outcomes, and greater individual well being", still staying in limited access order (North et al., 2013, p. 2).

A transition from LAO to OAO consists of two stages. The first involves creating institutions that ensure the possibility of impersonal relations within the elite. In the second stage, the dominant coalition comes to the conclusion that it is interested in expanding its impersonal relations beyond itself. A successful transition requires that the three following threshold conditions are met: 1) the supremacy of law for the elites; 2) the existence of public and private organizations created 
for an indefinite term; 3) consolidated political control over the armed forces, so that civilians make decisions on funding and declaring war. Once the threshold conditions are met, the transition from LAO to OAO will take around 50 years. In Great Britain and in the U.S., it occurred between 1800 and 1850. A faster transition was observed in Spain after 1975 (North et al., 2009, pp. 26-27).

A transition from LAO to OAO by directly borrowing institutions is unfeasible. After abolishing existing rents, a society with high crime levels would often appear instead of a competitive market economy, where rent-seeking plays an even greater role. "Policies from open access orders - universal, impersonal rights and rule of law; open access to markets; and greater political freedoms - reduce the natural state's ability to control violence. These changes therefore threaten to make people worse off, not better off." (North et al., 2009, p. 264). The explosive development of the Mafia in Russia during the 1990s is a compelling illustration of the correctness of this statement.

For the medium-term development of LAOs, it is important whether rents can encourage education and the growth of production potential. The positive influence of rents on production (aside from preventing violence) has been observed in many countries: in Chile, South Korea, sometimes in Mexico, Bangladesh and India (see North et al., 2013, p. 13). An obvious example is state support for large firms during "economic miracle" periods, particularly the chaebols in South Korea."In Korea, even though the chaebols concentrated the control of the industrial economy in a few hands and benefited from government protection of their oligopoly position, they did accumulate capital, improve their technology, and succeed in competitive international markets. Later the government was able to trim back the special economic privileges it gave to the chaebols..." (North et al., 2013, p. 15). "Natural states are not sick. Natural states have their own logic; they are not dysfunctional" (North et al., 2009, p. 269).

This leads to an important conclusion: "For concrete policy applications, helping LAOs to make their organizations more durable and rule-based is usually more useful for development than trying directly to promote the appearance of fully open economic and political competition in societies where threats of violence perpetuate limited access arrangements" (North et al., 2013, p. 19). This is none other than a sharp criticism of international organizations, i.e. the IMF, World Bank and the policies of developed countries, especially the U.S., who have tried and are still trying to directly impose Western institutions on developing countries. Moreover, this is the main difference between the NWW theory and the AR theory; in fact, this statement points to a fundamental flaw in the latter.

\subsection{Socioeconomic development as an emancipation cycle}

In his monograph, which received prestigious awards, Welzel (2013) suggests a general theory of economic development as an emancipation cycle. According to his theory, the growth of intellectual, communicative and material resources leads to the formation of common emancipative values that result in collective actions. As a consequence, the government is forced to guarantee freedoms, thereby asserting human rights. This frees up the creative abilities of people, promoting technical progress, which leads to growth in resources, and the cycle closes. 
The author constructs an emancipative values index (EVI) based on 12 indicators that are divided into four groups. Group one consists of respondent answers to the question whether they consider independence, imagination and obedience to be desirable qualities for children. The second group of questions finds out how acceptable the respondents consider divorce, abortion and homosexuality. The third group of indicators identifies respondent attitudes towards gender equality. Finally, the fourth group reflects whether the respondents value the ability to express their opinion. Welzel built the EVI for 95 countries representing over $90 \%$ of the world's population. Using the index, he conducted numerous econometric calculations demonstrating the existence of the emancipation cycle and, in the author's opinion, disproving the theory of Acemoglu-Robinson, according to which inclusive institutions play a decisive role in social development. ${ }^{4}$

\subsection{Comparison and critical analysis of the theories}

Diamond's theory reveals reasons for Eurasia's leadership, but does not explain the differences in development levels between different regions and countries on a single continent. Moreover, it does not address the mechanisms which enabled the spatial diffusion of knowledge and technology; to answer it, we would have to turn to the study of the culture and institutions of ancient and medieval societies.

Acemoglu and Robinson consciously ignore the role of culture and reform methods, referring to the experience of the two Koreas and the city of Nogales. We will delve into these examples below. At this point, we will only note that, without the idea of consistency between transitional institutions and culture, it is difficult to explain why the "iron law of oligarchy" had no effect in "economic miracle" countries and why extractive Chinese institutions have not prevented China from growing rapidly for almost 30 years.

Four years after the publication of the monograph on inclusive institutions, the article by Acemoglu and Robinson (2016) was published, where the authors took a considerable step towards responding to their critics. At the same time, they argued with the popular point of view by which elites play an important role in transitioning to inclusive institutions. Acemoglu and Robinson attempted to prove that social norms and informal institutions are of crucial significance; reformers only need to fix those institutions in legislation.

Considering the emergence of the Athenian democracy, the authors wrote: "Though reforms were legislated by Solon and Cleisthenes, they were institutionalizing and codifying a political equilibrium that already existed..." (Acemoglu and Robinson, 2016, p. 9). ${ }^{5}$ Meanwhile, shortly after the Solon reform, Pisistratus' tyranny was established in Athens, and it required more than 50 years to return to democracy within the framework of another administrative system built by Cleisthenes. This situation is very close to the path followed by many countries as a result of premature attempts to implement democratic institutions and indicates that the Solon reforms were inadequate for the mass culture. It should also be noted that only $15 \%$ of Athenian population had voting rights. The participation of citizens in politics and administration was paid for largely with the labor of

\footnotetext{
4 For a more complete overview of Welzel's theory, see Polterovich (2017d).

5 References cited are from to the web version of the article.
} 
slaves and metics, as well as with taxes collected from subordinate cities (Rhodes, 1998). Thus, within the framework of the dichotomy adopted by Acemoglu and Robinson, Athenian institutions can definitely be called extractive.

Moreover, there are sufficient grounds for questioning the efficiency of voting institutions, which call for a direct expression of will concerning issues that require professional competence. Athens had no regular education system, so the majority of citizens were most likely illiterate. They would inevitably fall victim to skilful demagogues. Rhodes (1998) and Ober (2015) cite facts confirming this statement. Rhodes wrote: "This administrative system was apparently unprofessional and inefficient. Its ultimate task more likely consisted in demonstrating loyalty than skill: every loyal citizen had to play his own role in the system. It was "fair" not in that it executed decisions made by the citizens, but in the very fact of their involvement in the process" (Rhodes, 1998, p. 47). This explains why, despite the numerous experiments, democracy achieved full scale and stability only in the $20^{\text {th }}$ century, after reaching mass literacy and building modern systems of government administration.

The greatest methodological deficiency of the AR theory, unnoticed by its critics, is that the inclusivity of institutions - freedom of competition and its legal protection - does not exclude the exploitation of one part of the society by the other. In a sense, inclusive institutions may also be extractive at the same time. The dichotomy and unclear definitions of the main concepts significantly limit the explanatory power of the Acemoglu-Robinson theory.

The NWW theory explains the long-term evolution of institutions in human communities on a more detailed and deeper level. It may seem that the concepts of limited access orders and the extractive institutions coincide in content. However, this is not entirely true: the former is focused on the limited participation of the population in decision-making and on the level of coercion (violence), while the latter is focused on rent extraction. Due to this nuance, in the framework of the North-Wallis-Weingast theory, it became possible, in principle, to differentiate the role of rent extraction, depending on the development stage. However, this approach has not been sufficiently elaborated and, in most considerations, limited access orders and extractive institutions are indeed synonymous.

The NWW theory appears incomplete in a number of other important aspects as well. It remains unclear what exactly prevents the achievement of threshold conditions in most countries and whether they are sufficient for a transition to OAO. To answer this question, we need to include the evolution of civic culture in the consideration. However, the NWW theory, not unlike the AR theory, does not really take cultural factors into account.

Both open access orders and inclusive institutions in the AR theory are presented as the pinnacle of development, as a kind of "the end of history." This conclusion results from the fact that the main concepts are "rough" and not fully elaborated. In the NWW theory, violence is viewed as physical action (or the threat thereof) contrary to the law or resulting from a "repressive" regime. However, access (participation) is in fact considered on a binary scale: it is assumed that "free" competition automatically ensures "access." Meanwhile, open access orders practised capital punishment for bankruptcy and incarceration for price collusion. What are they, if not forms of violence? And can market access be considered free, if a loss in competition is likely to lead to pauperism? 
Modern OAOs also rely on violence to a considerable extent. The fact that it is impersonal does not mean that it is "fair" and "efficient." The rules of the game themselves may create privileges for a given group of participants. In the simplest scenario, "perfectly neutral" rules mean that the winner is the one who is the strongest at the moment. However, this effectively limits access, for the weaker. Thus, impersonality does not ensure genuinely free access, and it would be more reasonable to call modern OAOs as impersonal access orders (IAO).

At the same time, as many examples show, the involvement of the general public in the political process hardly guarantees an efficient and "non-violent" nature of decision-making. As society develops, violence (and, more generally, coercion) becomes costlier due to cultural changes, i.e. the increased social costs of human suffering and individual moral costs. This is why IAOs should develop, becoming orders of general collaboration. In the second part of the paper, we will attempt to elaborate on this idea.

The idea of the dominant role of institutions in the socioeconomic development process seemingly arises due to the fact that formal institutional changes are introduced through respective laws, the execution of which may be supported by coercion. In any case, Acemoglu and Robinson, referring to the example of the two Koreas, could have used this argument.

This path of repressive evolution has been observed elsewhere besides North Korea. However, even in this case, the role of civic culture must not be underestimated: the cultural parameters of the elite determine the structure of the institutions which it imposes upon a society. If an institutional reform involves increasing the level of coercion and this level can be maintained by the elite, then the new institutional system can exist long enough and deform mass culture so that it becomes adequate for the existing institutions. The threat of violence forces people to adapt to the existing rules. Dissidents become isolated or eliminated. Behavior that is compliant with the law gradually becomes the norm; civic culture adapts to the institutions, temporarily contributing to their stability.

It should be emphasized, however, that excessive reliance on violence, while suppressing the initiative of citizens, leads to their passive resistance, prevents the growth of resources at the country's disposal and, ultimately, results in internal conflicts and a loss of competitiveness with other countries. As soon as the elite, while changing the institutions, sets the objective for a country's development, it faces the impossibility of ensuring their efficient functioning through violence. If the reform program does not take into account respective constraints in resources, technology, institutions and culture, then legally implemented institutions become dysfunctional (Polterovich, 2007). Thus, in order to explain social evolution, all of these factors need to be taken into consideration.

Another example of development where a dominant role seems to be played by institutions is found in integration, i.e. where a region is legally integrated into a more advanced institutional environment. An example, which plays a perhaps decisive role in the arguments by Acemoglu and Robinson, is joining the northern part of Nogales, a city populated mostly by Mexicans, to the United States.

The two parts of Nogales were officially divided by a wall and assigned to different countries in 1918. Evidently, over 100 years, significant differences should have gradually developed not only in the level of well-being of their citizens, but also in the civic culture, since each of the two resulting cities developed 
under the dominant influence of its respective country. The present-day website for the American Nogales ${ }^{6}$ names six prominent businessmen who have made significant contributions to the city's economic development. None of them was native Mexicans and only one of them lived in Mexico for some time. In building their businesses in Nogales, they all relied on their connections with business communities in other U.S. cities. It would be natural to assume that American Nogales actively borrowed educational programs, technology and cultural norms from more advanced U.S. regions. Both the Arizonian and federal government provided financial support to the city in various forms. ${ }^{7}$

Transformational costs, which could have turned out to be excessively high due to cultural and other factors and thus hinder the adaptation of more advanced institutions, were covered at the expense of external sources. In the vast majority of situations, the opportunities for reformers to use those resources are highly limited. Accordingly, the potential for evolution through integration does not prove the dominant role of institutions.

Welzel's theory presents the development process (with insignificant qualifications) as if technical progress and the growth of common resources alone activate the values of freedoms, which, in turn, is enough to accelerate technical progress and increase common resources. The mechanisms realizing these relationships are not considered. The author does point out this flaw in his theory, but believes it too difficult to overcome (see Welzel, 2013, pp. 281-282).

This approach is partly justified by the fact that econometric methods (Welzel's basic instrument) in principle do not produce strict evidence of any causality. However, the paper lacks a respective qualitative analysis. Moreover, the author deprives himself of the opportunity to perform such an analysis by considering institutions as a result, rather than the cause of development (Welzel, 2013, p. 14). Welzel believes this statement to be confirmed by calculations showing that the human rights indicator, which he built, depends on the level of emancipative values, whereas backward influence is not revealed statistically or is too weak. Thus, the Acemoglu and Robinson (2016) theory of the decisive role of inclusive institutions in socioeconomic development is disproven (Welzel, 2013, p. 169).

There are grounds to believe Welzel's conclusion regarding the insignificant role of institutions to be a consequence of his methodology. The author's emancipative values index does not directly incorporate the vital characteristics of civic culture, such as generalized trust or the level of corruption. Although the author shows that the EVI correlates with other cultural indicators, this may have been insufficient for an adequate assessment of the effect that institutions have on culture. In addition, the EVI reflects comparatively recent changes in civic culture and therefore can hardly be used to characterize development prior to the second half of the $20^{\text {th }}$ century.

At the same time, as an argument against the Acemoglu and Robinson approach, Welzel's conclusion is not unfounded. Indeed, those authors assert an

\footnotetext{
6 http://nogalesusa.com/heritage/nogales-families/

See, e.g. https://evogov.s3.amazonaws.com/media/81/media/15861.pdf and http://www.azplanningcenter. com/Nogales/Files/2010_08_20-000-ExecutiveSummary_IntroductionAndOverview.pdf, where it is stated directly that "the problems of Nogales (Arizona) are addressed at the federal, state, and local levels..." (p. 3).
} 
intricate connection between inclusivity (the participation of large population groups in economic activity) and protected private property, an impartial judicial system and equal opportunities for all citizens to participate in economic activity (Acemoglu and Robinson, 2012, pp. 74-75). In this context, it would be quite reasonable to measure the quality of institutions through the human rights index. However, the numerous attempts at shock democratization of backward countries have shown that expanding human rights under conditions of poor civic culture most often results in the intensification of rent extraction processes, falling output and, consequently, a return to authoritarianism. Thus, civic culture is, above all else, a pre-requisite for expanding human rights, while the reverse effect is quite likely to be weaker. However, Welzel's theory also fails to examine the internal causes of social evolution and, in particular, the question of what can be done to improve civic culture under "poor" institutions.

To answer this question, we will consider two different types of development. The first is commonly called catching up development. These are countries with a relatively low level of well-being and low quality institutions and civic culture. The objective for these states is to converge with developed countries. Few have managed to succeed, but their experience is especially valuable. The success of catching up development is called an "economic miracle." Striking examples include the East Asian tigers, post-war France, Spain in the 1960s and Ireland in the 1990s. China and Malaysia have recently demonstrated rapid and sustainable economic growth. Extensive literature is dedicated to the study of "economic miracles." Below we summarize and make certain additions to Polterovich (2016a, 2016b), demonstrating that changes in institutions and culture need to be coordinated in order to achieve success.

The other type of development is characteristic of leaders, which include Great Britain and its "offshore areas" — the United States, Canada, Australia, New Zealand, as well as continental Western Europe. The difference between the two types is conventional to a certain degree. Almost all countries had to catch up in different periods, therefore, for example, France and Spain should be attributed to different types in different periods. Part II of this paper studies leading development.

Before turning to the issue of catching up development, it is useful to clarify how the terms "institution" and "civic culture" are futher understood. It is well known that there are significant discrepancies herein (see, e.g. review in Alesina and Giuliano, 2015). Our formulations below are close to those used in literature and, of course, do not pretend to be precise.

In a system with multiple interacting agents, we call an institution a set of norms (behavior rules for those agents) forming a certain whole. The norms may be formal or informal. Compliance with the norms is maintained through positive and/or negative incentives but is also affected by the characteristics of the agents. Norms and incentives only constrain their behavior to a certain extent, but do not conclusively define it. Therefore, an institution "transferred" from one environment to another may become dysfunctional.

A group of agents acting within the framework of an institution to achieve common goals is called an organization. A term like "firm," "stock exchange," "agency" etc. can be a reference to an institution or organization of a certain type. 
Quite often, governance strategies are not classified as institutions due to their relatively short-term nature. This distinction does not appear to be convincing, especially where a certain type of policy is characteristic of a sufficiently long stage of development.

Behavior mechanism is determined by a combination of respective norms, incentives and characteristics of the acting agents. A mechanism can evolve even if the formal rules remain unchanged.

The concepts of competition, power and collaboration, relevant for further discussion, are considered in Polterovich (2017b). We will not dwell on them here.

We understand the term "civic culture" as a set of attitudes of a typical individual to other individuals, social groups and institutions, of his expectations, wordviews and values, as well as of his sociopsychological characteristics determining his functioning within various institutions. In the processes of socioeconomic development, an important role is played by such elements of civic culture, measured by surveys and experiments, as generalized trust, tolerance, the value of freedom of choice, the length of individual planning horizons etc.

\subsection{Catching up development: the connection between culture and institutions}

As noted above, Welzel's conclusion regarding the primacy of civic culture over institutions is based on the fact that his index of emancipative values served as a relevant determinant of the human rights index, whereas no reverse effect has been established. However, the human rights index is hardly an exhaustive characteristic of an institutional system. In order to study the mutual influence of institutions and culture in developing countries, one needs to distinguish between institutions of human rights and political freedoms (IPF), institutions of a competitive market (ICM) and institutions of catching up development (ICD) (Polterovich, 2016b). IPFs more or less ensure the equality of all citizens before the law, the right to elect and be elected, the freedom to receive information, express opinion, travel, establish political parties and public organizations etc. ICMs are responsible for the freedom of competition, property protection, restrictions on corruption, lobbying and monopolies.

However, as shown by numerous studies, attempts to "directly" improve IPFs and ICMs by passing legislation have not succeeded, primarily due to cultural constraints. The population of many developing countries is characterized by (see Polterovich, 2007, Section 6.9): disrespect towards the law, which leads to surges in corruption and rent-seeking if freedoms are expanded; paternalism and shortradius collectivism; manipulability; low levels of institutional and interpersonal trust; short planning horizons; low governance culture and authoritarian thinking style by the rulers. Numerous attempts of shock therapy (abrupt changes of economic and political institutions) in developing countries have usually resulted in falling output, deteriorating cultural characteristics and a return to authoritarian methods of governance.

The comparatively rare cases of "economic miracle" are associated with gradualist reforms which used catching up development institutions as interim ones (Polterovich, 2007, pp. 55, 136); they are able to function in a relatively backward cultural environment. ICDs include the corporatist system of governance, the general development agency, indicative planning, a national innovation sys- 
tem orientated towards technology borrowing and coupled with active industrial policy, mechanisms for maintaining an undervalued exchange rate, progressive personal income tax etc. While initiating economic growth, they simultaneously accelerate the evolution of civic culture, creating conditions for improving IPFs, ICMs and ICDs themselves (Polterovich, 2016a, 2016b).

Let us consider why it is that the ICDs provide effective tools which enable entirely different backward countries to catch up with advanced economies within 15 to 25 years. Solving a task like that requires realizing the "advantage of backwardness" (A. Gerschenkron), i.e. the opportunity to borrow technologies and governance methods that have proven to be effective in other countries. Technology borrowing by individual firms will inevitably face serious constraints, such as the lack of suitable raw materials, equipment or demand for new products. To use the backwardness advantage, large-scale modernization projects are needed which affect different vertices of the production graph. This leads to the need for planning. However, as practice shows, effective plans cannot be "imposed from above." Their development and implementation requires positive collaboration (Polterovich, 2017b) with all main social groups. Their actions need to be coordinated, not suppressing but, on the contrary, encouraging initiative while simultaneously controlling rent extraction opportunities. ICDs can solve these tasks by complementing each other.

The political regimes in Southeast Asian countries and in the majority of other "economic miracle" countries took into account the paternalist expectations of their populations. The decisive role belonged to the state. However, the governance system was based on corporatist principles, which required close interaction between government authorities, business associations and trade unions, as well as taking consumer interests into account, conducting inequality reduction policies and targeting government officials at all levels towards ensuring economic growth under a sufficient degree of decentralization. Explicit and implicit agreements between workers and employers mitigated class conflicts, while strengthening institutional and interpersonal trust.

Indicative planning played a vital role in the administration and consolidation process. P. Masse, who created the world's first such planning system in post-war France, wrote: "The Plan is worked out through a concerted effort by representatives of economic and social forces: civil servants, management (agricultural, industrial, commercial), trade unionists, and workers. This collaboration makes for more coherent forecasting and decisions, and it creates a feeling of togetherness which is favourable for the implementation of the Plan" (Masse, 1965, p. 265).

A number of collaboration institutions acting in the countries of catching up development relied on collectivism and successfully overcame difficulties arising due to the short radius of interpersonal trust and the imperfections of market institutions. They include the main bank system and the lifelong employment system in post-war Japan and other Southeast Asian countries, township and village enterprises in China in the 1980s and building and loan associations (Bausparkassen) in West Germany and Austria after World War II. As well-being improved, so did civic culture, while the role of the state diminished gradually; the ICDs were losing their significance, giving way to institutions of economic and political competition. 
The ICD concept answers the question raised in North et al. (2013, p. 2), on which we have mentioned earlier: "How remaining in a limited access order to improve social organization in order to increase output, reduce violence, ensure a stable political system and improve the individual well-being of citizens?" Reformers should introduce institutions capable of initiating and maintaining economic growth under cultural and other constraints, while weakening them, ensuring the potential for future institutional transformations. ${ }^{8}$ An important and understudied question is why do the vast majority of developing countries fail to follow the strategy which, as noted above, could lead them to success? The question is partly answered in Polterovich $(2014,2017$ a).

\subsection{Final remarks}

The AR and NWW institutional theories discussed above offer no satisfactory explanation for the social development process. It remains unclear why extractive institutions (limited access orders) have dominated throughout almost the entire human history and what were the causes and mechanisms by which they gave way to inclusive institutions (open access orders) in the $20^{\text {th }}$ century. Welzel's theory of the emancipation cycle also contains no analysis of causal connections, leaving unaddressed the mechanisms which drive the evolution of civic culture; his main development indicator (the emancipative values index) could hardly serve as an informative characteristic of societies before World War II. Moreover, all of these theories treat modern competitive society as the pinnacle of civilization, without even trying to identify any trends for future socioeconomic evolution.

The objective of the general theory of socioeconomic development is to explain the structure and alterations of the organization of human communities, including the spheres of foreign and domestic political and economic interactions. Our analysis demonstrated that the attempts to address this task, based on considering only geographic or institutional or cultural factors, do not lead to success. Moreover, as noted above, studying development only by characterizing the degree of involvement of the general public in the political process is unproductive, since the involvement may signify an exhausting political or economic struggle as well as a constructive dialogue. We need a better differentiated analysis of the evolution of interaction mechanisms between individuals and their communities.

The development trajectories of various countries differ greatly even within Western civilization. Identifying general patterns requires a rather abstract level of analysis. In the second part of this paper, I will attempt to investigate how the interrelation within the three main mechanisms of coordination (competition, power and collaboration) changed in the process of evolution.

Unlike the authors of monocausal theories, I believe it is necessary - in order to explain socioeconomic development - to consider the mutual influence of institutions, civic culture, technical progress and levels of well-being; it is also advisable to take geographic factors into account. The idea of North-Wallis-

\footnotetext{
8 In terms of the reform theory, the issue is to build promising institutional trajectories (see Polterovich, 2007, Ch. 7 and Section 4.7). The ICD concept is discussed in more detail in Polterovich (2016b).
} 
Weingast regarding the reduction of the role of violence, which, in our opinion, not only acts as an attribute of power but also of competition, will be expanded. During the past 100 years, both of these mechanisms have been giving way to institutions of positive collaboration in developed countries (Polterovich, 2015, $2017 b$ ). It would be natural to encourage this trend further, realizing that it has no satisfactory alternative.

\section{Part 2. Evolution of coordination mechanisms}

\subsection{Introductory notes}

Part two of the article is dedicated to leading development; here we are in fact dealing with the evolution of Western societies. We will show how, as a result of mutually caused changes in culture, institutions, technical progress and the level of well-being, specific forms and combinations of the three main coordination mechanisms emerged at every stage of evolution. We stress the significance of ideology and the phenomenon of technical progress in shaping the institutions of economic and political competition, which, in turn, contributed to the development of an ideology of social progress and the formation of the welfare state. These changes, along with economic growth, created the conditions for further transforming civic culture: increasing the levels of trust, tolerance, altruism and cosmopolitanism and extending the planning horizon. We demonstrate a decreasing level of coercion built into the mechanisms of power and competition and an expansion of the role of collaboration. We put forward a hypothesis that the speed of these processes depends on geographical factors. In conclusion, we discuss the idea of the welfare world.

By investigating the mutual influence of coordination institutions on the economy and the culture, we gain the opportunity to explain the process of socioeconomic evolution, abstracting from the specifics of particular countries. Of course, applying this pattern to the history of each country will require specification and elaboration. However, the main driving forces for development and the causal connections examined below are invariants of different modifications of leading socioeconomic development.

The development of the approach applied here ("philosophy of collaboration") began in the articles (Polterovich, 2015, 2017b, 2017c), mostly based on materials from the $19^{\text {th }}$ and $20^{\text {th }}$ centuries. The time range in this paper has been expanded considerably. Realizing my plan, I rely on the works of Fukuyama $(2011,2014)$ and Mokyr $(2005,2016)$ that emphasize the role of culture in the development of the state and stress the significance of the idea of technical progress.

\subsection{War, civic culture and the formation of power mechanisms}

The four main types of human societies are usually distinguished as: band, tribe, chiefdom and state (Diamond, 1997).

Bands of human species (10-50 persons) were engaged in gathering in an era when other forms of human communities did not yet exist. Historically, collaboration became the first coordination mechanism. This mechanism was set genetically and based on the natural altruism of parents towards their children. 
According to the Hamilton law and numerous studies, kinship altruism also applies to distant relatives, although the level of altruism diminishes with the degree of kinship (Birch and Okasha, 2015). Genetic predisposition provided the foundation for expanding collaboration - the formation of tribes and then chiefdoms. The most primitive form of civic culture, which included trust towards relatives and suspicion towards outsiders, was a natural consequence of biological evolution, based on the awareness of kinship relationships. As the size of communities increased, relationships became increasingly harder to identify. As a solution to this task, an initial form of religious consciousness appeared, i.e. a cult of ancestors that cemented the society.

The formation of larger and structurally more complex communities took place under the influence of four main factors: the threat of attack, limited resources, the will to collaborate and changes in resource production technology. Technological changes - animals domestication and the development of agriculture-encouraged the emergence of land ownership. It had to be protected; at the same time, an opportunity appeared to increase consumption through expanding land plots. Carneiro (2002, pp. 90-91) names two main tasks of chiefdoms: capturing prisoners of war to be used as slaves and seizing territories to force new subjects to pay tribute and provide warriors in case of war. Chiefs relied on violence and a hierarchy of administrators. In chiefdom administration algorithms, kinship also played a key role. Kinship remained the source of behavioral altruism and, consequently, a genetically set will for short-radius collaboration. Collaboration ensured the survivability of communities in the processes of external competition.

Often, collaborative mechanisms are built into competitive mechanisms, so that the complete destruction of the enemy contradicts the interests of the opponents. In this concrete case, we are talking about another factor of genetic nature - exogamy, which necessitated the exchange of women between groups. Such exchanges could serve as a conflict resolution mechanism (Fukuyama, 2011, pp. 54-55). In addition, it was an incentive for groups to unite.

Thus, the two very important coordination mechanisms - collaboration and external competition - are of genetic origin. Mechanisms of power emerged as a result of the need to fight competitors, relying on vertical coordination. Civic culture originated from genetically set behavioral norms, instincts, while ensuring an understanding of the advisability of the power hierarchy and, consequently, a certain degree of voluntary participation in power mechanisms. Thus, they relied not only on coercion but also on the willingness to collaborate.

A conclusion suggests itself that, at the dawn of civilization, the development of human communities was far from being consistent with Welzel's emancipation cycle. The most important elements of culture - trust towards relatives, exogamy - were set genetically and the improvement of institutions resulted not so much from the growth of resources but under the influence of their scarcity.

The role of kinship relationships gradually becomes weaker as the state emerges and develops. The rules for power formation, the functioning of armed forces, law enforcement agencies and courts are formalized and depersonalized, becoming laws.

The need for professional administrators and war commanders leads to the emergence of an elite. The elite had to be educated, trained and therefore 
already freed from physical labor. The elite material needs are satisfied at the expense of other members of the society which it serves and which is not rich enough to provide educational services to all of its members. In natural states, limited access orders are not only not dysfunctional, as North and his co-authors wrote; they are necessary. Power in a poor society should inevitably rely on extractive institutions. Inclusive institutions (open access orders), which dominated as collaborative mechanisms in the initial development stages, are losing their significance, being relocated to the lower, communal levels of the power hierarchy.

C. Tilly, one of the founders of the modern theory of the origin of the state, wrote that "war made the state, and the state made war." Citing these words, Fukuyama noted that Tilly had relied on the history of Europe; however, this conclusion also applies to China (Fukuyama, 2011, p. 94). There are doubts with respect to Latin America and certain other regions, since large-scale armed conflicts were unusual for them. However, in all cases, external political competition (a threat of war, in particular) became the most important motivation for the organizational progress, the formation of power mechanisms (Thies, 2012).

Power would require too high a cost and could not be stable relying on violence alone. Its second most important pillar was ideology, which shaped an appropriate type of civic culture aimed at collaboration. Carneiro wrote: "Ideology... may eventually become an elaborate, coherent, and compelling system of beliefs and practices... this ideology may in time penetrate so deeply in a chiefdom's traditions as to obscure and belie its true roots. The ruthless conquests of a military despot may, in a few generations, become transmogrified into a peaceful and benevolent joining of willing peoples by an ancient leader who, if not a god himself, was at least guided by a divine hand" (Carneiro, 2002, pp. 92-93).

Religion, shaped around a cult of ancestors, played an enormous role in forming a single society and cooperative behavior. Fukuyama stressed this: "In large groups, it becomes harder and harder to monitor the individual contributions of members; free riding and other forms of opportunistic behavior become much more common. Religion solves this collective action problem by presenting rewards and punishments that greatly reinforce the gains from collaboration in the here and now. If I believe that my tribe's chief is just another fellow like me following his own self-interests, I may or may not decide to obey his authority. But if I believe that the chief can command the spirits of dead ancestors to reward or punish me, I will be much more likely to respect his word. My sense of shame is potentially much greater if I believe I am being observed by a dead ancestor who might see into my real motives better than a live kinsman" (Fukuyama, 2011, p. 37).

It is no accident that, in early states, a religious elite was formed along with the military elite: ${ }^{9}$ religious rites required knowledge and, accordingly, time costs incompatible with the independent satisfaction of material needs. The extractive nature of institutions was an essential condition for survival of

\footnotetext{
9 North, Wallis and Weingast wrote about the Aztec state: "The combination of religion, education, and politics created a dominant coalition with a strong identity, clear shared beliefs with strong educational roots, and limited access" (North et al., 2009, p. 57).
} 
states and still remains an inevitable consequence of the existence of power mechanisms. ${ }^{10}$

Along with religion, secular customs also carried high significance. As an example, Carneiro cites the tax payment holiday practised on Fiji Islands, which was accompanied by songs and dance and culminated with a feast at the King's invitation (Carneiro, 2002, p. 94).

Society's internal organization changed as a result of external competition. Cultural changes ensured the stability of new institutions and created opportunities for their further improvements. External competition - war and its constant threat - acted as the most important factor for technological change. This is what the authors of $A$ History of Science and Technology wrote: "The process of forming kingdoms and empires involves warfare in nearly all cases. Thus, military technology is often at the forefront of change. War chariots preceded carts used for hauling goods by hundreds of years. Copper, bronze, and iron were employed in battle axes and arrowheads well before they became common as the tips of plows or in needles" (Bunch and Hellemans, 2004, p. 4).

Since their inception, the protection of subjects and conquering new territories were the basic functions of chiefdoms and then states. However, the need to maintain administration bodies, the military and religious elite forced governments to take care of the economy as well. Up until the $12^{\text {th }}$ and $13^{\text {th }}$ century, they limited themselves to creating infrastructure and constructing irrigation structures. The development of industry was included on the list of the most important tasks for European states following the invention of firearms. According to A. Gabor, "an unprecedented arms race" began in the $14^{\text {th }}$ century. "In order to participate effectively in the attendant inter-state rivalry, monarchs had to create their indigenous weapon industries or supply the necessary weaponry otherwise... Apart from paying and feeding the troops, arms production and shipbuilding constituted the most burdensome challenge for early modern states..." (Gabor, 2005, p. 2).

In Chang (2003), it was noted that in the $14^{\text {th }}$ century, English monarchs used a policy of taxes, duties and trade barriers to stimulate domestic production. Since the beginning of the $16^{\text {th }}$ century and, especially, in the $17^{\text {th }}$ century, the ideas of mercantilism became widespread in England and France. The governments of these countries made extensive use of tariffs, subsidies and direct bans on imports to support a positive trade balance and stimulate domestic industry. The logic of this policy was a continuation of war logic: benefits had to be gained at the expense of trade partners.

At the same time, domestic economic policy was aimed at hindering competition. Through guilds, rules were established that prohibited setting prices for products below a certain level. Advertising of manufactured goods was considered a violation of ethical norms. In addition, multiple trade barriers were imposed within each state's territory: fees for entry to cities, passage through bridges, the right to trade etc. (Kulisher, 1922; Ogilvie, 2014).

Medieval restrictions on competition are usually deemed to have played a negative role, hindering development. This is not evident, however. Price fixing

\footnotetext{
${ }^{10}$ Another thing is that at a certain development stage, "the degree of extractivity" of political and economic institutions begin to decrease (see below).
} 
prevented price wars, which, given small market sizes, could have negative consequences. Tariffs on the movement of goods were possibly the most effective method for tax collection given the lack of a reliable accounting for taxpayers and production and consumption volumes.

War ceased to be a dominating factor in economic policy as a result of the formation of another, more effective mechanism for increasing public resources, i.e. the innovation economy. For this to happen, the ideology of the "golden age," orientated towards maintaining the existing norms and customs, had to give way to the ideology of social progress.

\subsection{The idea of progress and the shaping of competitive economic mechanisms}

As historical experience shows, armed confrontation between several states in a limited territory could result in two types of equilibrium: the formation of a united empire spanning the entire territory or the co-existence of those states constantly threatening each other and fighting each other from time to time. Being stable within a limited time frame, both types of equilibrium were prone to characteristic long-running transformations. In the first scenario, we see the activation of the struggle between the elites and the general public for resources that were not growing in quantity. Palace coups and civil conflicts exhausted the resource base, while the lack of clear development goals led to rejecting innovations and the decay of the ruling class. As a result, the empire became easy prey for unexpected conquerors. This pattern has been in place throughout all human history. Examples include the Roman Empire and the Qing empire.

For example, between the 1670 s and the 1760 s, China fought only offensive wars and had no strong opponents. By the middle of the $18^{\text {th }}$ century, Hongli, an emperor of the Qing Dynasty, "perceived himself to be king of the world" (Nepomnin, 2005, p. 132). He pursued a policy of isolating China, focusing on traditional values and suppressing innovation. This caused an imbalance to accumulate between the growing population characteristic of peaceful periods and the potential of the economy. In the $1770 \mathrm{~s}$, a sequence of local riots took place and in 1796, the Peasant War broke out which lasted for 8 years and "became the breaking point in the buildup of the Qing empire's crisis" (Nepomnin, 2005, p. 364). By the end of the $19^{\text {th }}$ century, the empire became divided into areas of influence between Western European powers and Russia.

The second type equilibrium is much less common. Examples include Polynesia and African countries before the arrival of Europeans; in both cases, the opposing sides were divided by natural obstacles and the resulting equilibrium was upset by the invaders. Europe is a unique case in this respect. Over a thousand years following the conquest of Rome by German tribes, this continent was shaken by endless wars. The Hundred Years' War of 1328-1425 demonstrated that a conflict with neighbors does not lead to the expected benefits. Advanced European states switched partly to conquering richer, remoter territories that were less capable of resistance. The great discoveries even more clearly demonstrated the importance of astronomical knowledge and technical devices, especially transport vehicles. 
The arms race which began in the $14^{\text {th }}$ century could lead to an absolute victory for one of the opposing sides and to the formation of an empire covering the greater part or even all of Western Europe. In this case, the incentives for further improvement would be lost, leading to a new recession. This did not happen, however. To endure the long confrontation, leading European states had to make development of the economy a high priority. The confrontation contributed to the formation of a new culture, which ultimately resulted in a sharp acceleration in economic growth and the shaping of an ideology of public - social and technical — progress. With the emergence of new, far cheaper methods for expanding resources, war gradually ceased to be relevant both as a central policy tool and a leading element of the dominant ideology. The paradigm of state interactions and their internal organizations changed.

When considering the initial stage of this process, four historical eras are generally defined: Renaissance $\left(14^{\text {th }}-17^{\text {th }}\right.$ century), Scientific Revolution $(1543-1687)$, Enlightenment (1715-1789) and Industrial Revolution (1760-1840). ${ }^{11}$

"The European Enlightenment was a multifaceted phenomenon, much of it concerned with the natural rights of human, concepts of religious and racial tolerance, political freedom, inequality, legal reform, and much else. At the deepest level, the common denominator was the belief in the possibility and desirability of human progress and perfectability through reason and knowledge. The material aspect of this belief followed in the footsteps of Francis Bacon's idea of understanding nature in order to control her. Useful knowledge became the buzzword of the eighteenth century" (Mokyr, 2005, p. 4).

Finding a connection between an area of knowledge and production became a key discovery for this period. This idea, clearly formulated by D. Diderot in his Encyclopedia, came to fruition during the Industrial Revolution, when the leading researchers - G. Davy, J. Priestley and A. Navier — successfully combined their research activities and inventions (Mokyr, 2005, p. 9-10). During this period, there were established scientific societies (Society of Arts in England in 1754) and applied educational institutions (Grandes écoles in France, Mining Academy in Saxony, Royal Institute in England); scientific journals appeared (Journal of Natural Philosophy, Chemistry and the Arts, 1797).

At the initial stages, the development of arts, scientific knowledge and enlightening ideas became possible due to the aforementioned equilibrium which had formed in Europe. The presence of numerous ruling (king's, prince's etc.) courts encouraged the shaping of a peculiar market of artists and thinkers: each ruler tried to have famous persons amongst his subjects. Renown earned by unselfish labor provided an opportunity to receive material support. When the idea of progress took roots in the consciousness of the ruling elite, researchers were now able to compete for state-paid positions in academies and educational institutions (Mokyr, 2016).

One should have in mind that, up until the $20^{\text {th }}$ century, no invention could become widely spread in Europe without the formal approval of one or other ruler. The Industrial Revolution may not have taken place without the tough opposition of European states.

\footnotetext{
${ }^{11}$ The dates are quite conventional, there is no generally accepted periodization; moreover, these processes occurred in different countries at different times.
} 
Diamond wrote: "In fact, precisely because Europe was fragmented, Columbus succeeded on his fifth try in persuading one of Europe hundreds of princes to sponsor him... The story was the same with Europe's cannon, electric lighting, printing, small firearms, and innumerable other innovations: each was at first neglected or opposed in some parts of Europe for idiosyncratic reasons, but once adopted in one area, it eventually spread to the rest of Europe. These consequences of Europe's disunity stand in sharp contrast to those of China's unity" (Diamond, 1997, p. 413). The point is that Chinese rulers, without the pressure of external competition, driven by political intrigues, made decision after decision which hindered the development of China's economy. As a result, the weaving loom invented in the $14^{\text {th }}$ century never gained expansion in China and, in the $15^{\text {th }}$ century, naval expeditions were banned, shipyards were destroyed and the production of mechanical clocks was stopped.

J. Mokyr stressed, however, that the Industrial Revolution in Europe affected only a thin stratum of the elite, "a few tens of thousands of clever and dexterous mechanics and skilled craftsmen who could read blueprints, knew the properties of the materials they used, ... and had the experience to understand friction, torque, resistance, and similar concepts. For the rest of the labor force, education and literacy may not have mattered much and Britain's had no advantage in it" (Mokyr, 2005, p. 15).

The era of universal literacy in Western Europe came only by the end of the $19^{\text {th }}$ century. However, in the elite strata of society, the idea of public progress took root already by the middle of the 18 th century.

The Industrial Revolution was accompanied by vital institutional changes. In the late $17^{\text {th }}$ century, following the Glorious Revolution in England, patent law began to take shape and strengthening of contract enforcement law was started. However, as Mokyr pointed out, of no less - and possibly greater-importance was the removal of the numerous trade restrictions characteristic of the current regimes during the Industrial Revolution. By this time, the regimes had become an obstacle for potential trade expansion, which was made possible by the development of transportation vehicles, the discovery of new lands and the growth of production. Guilds resisted liberalization, and they were supported by part of the administrative elite, for which restrictions were a source of rent. In England, the guilds were relatively weak; some researchers believe that this partly explains England's leadership in the Industrial Revolution. In France, the guilds were dissolved by law in 1791, and the Napoleonic Wars accelerated their liquidation in other European countries as well. A certain effect on the outcome of the struggle was exerted by the theory of A. Smith, who linked the ideas of economic progress and free competition (Mokyr, 2005, pp. 19, 22).

Thus, the old inefficient institutions of collaboration, which led to the monopolization of local markets, were destroyed. At the beginning of the new stage, competitive mechanisms used to become tougher and then gradually softened, as new and more efficient collaborative mechanisms formed (Polterovich, 2015, $2017 \mathrm{~b}$ ). The most important factor in this transformation was technical progress, which, along with trade, promoted the transformation of economic interactions into a positive sum game.

The history of the development of the idea of progress, industrial revolution and the creation of competitive markets convincingly illustrates the interrelation 
and interdependence of the three factors of development: culture, institutions and the modernization of production technology, so not one of them should be considered dominant. The ideology of technical progress, unlike the ideology of armed confrontation, allows for the decentralization of control and coordination of interests on the basis of mutual benefit and, consequently, the use of horizontal collaborative mechanisms. However, for these opportunities to become a reality, a long evolution of social consciousness and institutions was required.

The proliferation of the ideology of technical progress amongst the elite strata of Western society did not lead to the immediate refrain from armed confrontations. Over 100 years passed after the end of the Industrial Revolution before war between Western European countries ceased to be an expected reality. ${ }^{12}$ Napoleon and other rulers of European states, who already possessed a new tool to improve well-being, were still prisoners of the old paradigm. This impeded the decentralization of governance and the development of democracy. Victorious wars were supposed to justify in the eyes of society - and possibly in his own eyes - Napoleon's appropriation of the emperor's crown.

"Twenty years of almost uninterrupted wars (beginning from 1792) completely drained France. Its direct irrecoverable losses amounted to around 1 million people. The country was tired of war. Young people evaded military service under any pretext, including self-injury" (Chubaryan and Mirzekhanov, 2014. p. 117). The role of the economy in the France's governmental policy grew over time. For example, "Napoleon III, to a greater extent than his predecessors on the French throne, understood the importance of economic progress. He surrounded himself with prominent economists and entrepreneurs... His government lifted restrictions on share capital activity..., signed a free trade treaty with Great Britain (1860), completed the large-scale reconstruction of Paris... Dramatic transformations occurred in transport vehicles: the country became covered with a dense network of railroads... In the $50 \mathrm{~s}$ and $60 \mathrm{~s}$, France achieved the highest rates of economic growth during the entire century. Moreover, the 'locomotive' of the French economy was modern, large, machine-driven industry... At the same time, the main support for the Bonapartist dictatorship was the top of the French army. Napoleon III, actively using the armed forces to achieve foreign political goals, completely quenched its thirst for victories, ranks, and awards" (Chubaryan and Mirzekhanov, 2014, p. 123).

\subsection{Development of institutions of political competition}

Throughout the greater part of human history, the main task of organized human communities - tribes, chiefdoms and states - was to capture the wealth and territories of others while protecting your own. Solving this task required a hierarchical organization of society, an ideology ensuring vertical collaboration between its members and the presence of an elite to command armies and to introduce the ideology into the general public's mind.

The elite inevitably had to be served by the rest of the society, but the level of respective costs depended on culture and current institutions. The pursuit of

\footnotetext{
12 To a great extent, this can be attributed to the asynchronous nature of the cultural development in the leading European countries, i.e. England, France and Germany.
} 
power and greater rents led to a constant struggle between elite groups, conflicts and coups. Technical progress increased the role of the economic component of social development, strengthening the industrial and commercial elites who began their battle for power. The formation of electoral democracy was to ensure societal stability and reduce the costs associated with the struggle between the elites. However, this process required huge expenses due to the gap between the levels of civic culture of the elite and the general public.

The most important reason here was the lack of education: the low demand for it from society and the state did not stimulate its development which, in turn, hampered the development of the economy and public institutions. However, an even deeper cause was the low level of well-being. Mass education is possible only if young people can postpone entering into a life of labor.

In 1910, the proportion of students in senior secondary school aged 10-19 did not exeed 2.8\% in England, France, Austria and Italy; in Germany, this proportion was $3.2 \%$. At the same time, the share of students between 20 and 24 did not exeed $1.35 \%$ in all the aforementioned countries except Austria, where about $3.8 \%$ of this age group attended universities (Volkov, 2017, p. 107). These figures not only confirm Fukuyama's statement that "Europe was not socially ready for democracy until the final third of the nineteenth century" (Fukuyama, 2014, p. 392), but also make it possible to strengthen it: actual preparedness came only after World War I. ${ }^{13}$

The painful process of developing democracy in Europe during the $19^{\text {th }}$ century was largely attributable to the fact that the ideas of social progress and universal equality, which conquered the minds of many in the educated class, were not thoroughly developed: too little was known about under what conditions and in what form these ideas could be realized. The ideology of violence as the main method of conflict resolution, which had dominated for thousands of years, fancifully existed alongside the ideas of building a fair democratic society. This is why dreamers carried away by Rousseau's ideas that all people are born equal and free and that the guardians of executive power are not the lords of the people but their servants, tried to realize those ideas through mass executions. Rampant abuse of power, crime and corruption, which followed still another revolution, prompted society to restore monarchy.

Thus, in the description of the coup of 18 Brumaire 1799, the authors of "World History" noted: "The elite of the Republican politicians generally sympathized with Bonaparte's pursuit of absolute power, manifested in the constitution. Its members were afraid of extremities like civil war, revolutionary terror or royalist counterrevolution. They had long dreamed of a 'strong hand', a dictator who would secure order and peace in France, as well as its protection against external threats. Bonaparte fully satisfied their expectations" (Chubaryan and Mirzekhanov, 2014. p. 115).

Moreover, at the early stages in the development of democratic institutions, the losing side had no guaranteed security. Quite often, political competition was only a prelude to traditional violence. In North et al. (2009, p. 203), we read: "When violence breaks out in natural states, losing factions are often killed,

\footnotetext{
${ }^{13}$ It should be noted that, to an even greater extent, a sufficiently high level of education is necessary to form long-radius institutions of collaboration.
} 
exiled, or otherwise eliminated. Bolingbroke provides an example. As secretary of state under Queen Anne (1702-1714), Bolingbroke had sought to eliminate the Whig faction..." When the Whigs took the upper hand, Bolingbroke was (extrajudicially) convicted by the parliament for eternal exile and deprived of his title and fortune. "The British actively restricted factions by the threat of death or exile, until the mid-eighteenth century."

The democratic mechanism based on majority rule, which was implemented in the $18^{\text {th }}$ and $19^{\text {th }}$ centuries, represented only the very first (though quite important) step towards reducing the costs associated with adopting social solutions, while inheriting certain traits of a traditional mechanism based on violence. North and his co-authors cited Washington: "The alternate domination of one faction over another, sharpened by the spirit of revenge natural to party dissension, which in different ages and countries has perpetrated the most horrid enormities, is itself a frightful despotism" (North et al., 2009, p. 208).

Voting rights, as well as access to education, remained a privilege for a tiny minority in many European countries up until World War I. In Great Britain, Austria, Italy, Belgium, Finland, Sweden and the Netherlands, comprehensive election rights for men were only introduced at the beginning of the $20^{\text {th }}$ century. In France and Switzerland, the male population obtained voting rights in the middle of the $19^{\text {th }}$ century. However, women in these countries had to wait another 100 years (Fukuyama, 2014. Table 6). The rapid expansion of election rights led to the negative consequences mentioned above. A gradual expansion was, however, necessary to avoid revolutions, which resulted from the discontent of certain strata of the population supported by a portion of the elite and driven by the ideas of social philosophers. Not infrequently, the ruling elite itself initiated reforms, hoping to attract new voters.

As democracy developed, its consensual form (Lijphart, 2012) and parliamentary committees appeared, which facilitated compromises not only in consensual but also in majoritarian democracies. Opposing parties in a number of countries began to receive financial support from the state. The costs of political competition decline due to incorporating collaborative mechanisms. Similar processes take place in economic competition as well (see more detail in Polterovich, 2015).

The emergence of an innovative economy facilitated the displacement of the traditional mechanism of foreign political competition (war) for three main reasons. First, due to the improved effectiveness of armaments, the costs of armed conflicts increased. Second, improved living standards for the population led to changes in values. In particular, the estimated damage resulting from human suffering increased. ${ }^{14}$ Third, demand appeared for mass education which, in turn, created conditions for the conscious participation of the general public in the political process; a declaration of war ceased to be the prerogative of a small elite group.

Levy and Thompson (2011, pp. 6-8) estimated the number of casualties in the greatest battles over the past 25 centuries. It turned out that in the $14^{\text {th }}$ cen-

\footnotetext{
${ }^{14}$ This is confirmed, for example, by the tradition, spread in the XX century, of announcing national days of mourning in the event of death of a small number of citizens by the standards of previous centuries (usually more than 100 in modern Russia).
} 
tury, the number of victims per battle was twice as high as in the $5^{\text {th }}$ century BC. At the beginning of the $19^{\text {th }}$ century, this number doubled again when compared with the $5^{\text {th }}$ century $\mathrm{BC}$, whereas, in the $20^{\text {th }}$ century, it increased tenfold when compared to the beginning of the $19^{\text {th }}$ century. At the same time, the frequency of wars between the leading powers decreased. Over the past 70 years, there have been no such conflicts at all.

The mechanisms of economic and political competition, having ensured growth in the resources at society's disposal, prepared the next stage of its transformation - the transition to a system based on the ideology of social peace and collaboration. A most important step in this direction was the building of the welfare state.

\subsection{The rise of the welfare state}

By the beginning of the $20^{\text {th }}$ century, the ideology and mechanisms of technical progress, combined with the ideology and institutions of free competition, acquired a decisive role in shaping the government policy of Western countries. However, as well-being and mass culture improved, society became increasingly more sensitive to the negative aspects of competitive mechanisms - high inequality, unemployment and overproduction crises. The 1930s crisis played a special role. The rise of fascists to power in Germany, Spain and Italy showed that, under such conditions, political competition may lead to the victory of destructive forces.

World War II consolidated societies both politically and economically in the countries that opposed to fascism. The forced use of centralized mechanisms for the distribution of scarce goods (e.g. food stamps in England) encouraged a change in the balance of power in the confrontation between market and dirigiste ideologies. A. Briggs cited one of the "white books" published by the coalition government of Great Britain in 1944: “...it is right for all citizens [from the viewpoint of morals], to stand in together, without exclusion based on differences of status, function or wealth" (Briggs, 1961, p. 13). In particular, the government declared fighting poverty and unemployment as its tasks.

At this time, the concept of "welfare state" became generally accepted. It marked a change in the understanding of the role of power. The need to unite during the war forced politicians to consider society as a single whole. Social services were to take care of not just the poorest, but all strata of the population. From then on, the government strove to ensure not just the minimum for everyone, as before, but "acceptable" levels of medical service, living conditions, employment and income. "There was thus a close association between warfare and welfare" (Briggs, 1961, p. 14).

This approach signified a recognition of the need for cooperative mechanisms in order to adjust competition, the "play of market forces." The increased responsibility of society for unfavorable accidents that could affect any citizen, marked the initial stage of the transition to a new understanding of the role of the state as an intermediary in horizontal collaboration between citizens.

Of course, the turn towards social welfare policy was prepared through lengthy discussions that lasted throughout the $19^{\text {th }}$ century between advocates of free 
market, who relegated the state to only the role of a "night watchman" and supporters of paternalistic and moderate socialist views on the role of the state (primarily Fabians). The development of democracy, the emergence of trade unions and workers' parties and the aspiration of politicians of different directions to attract the general public to their side were of great importance. Thus, political competition facilitated the mitigation of consequences and then limitatation of economic competition.

The introduction of progressive taxation should be considered as one of the important steps in the formation of the welfare state. In England, it was introduced in 1789 , but in the U.S. and in continental Europe, it became common only in the $20^{\text {th }}$ century (Westin, 2014).

The first pension system appeared in Germany in 1889. By the beginning of World War II, pension systems operated in the majority of western countries, with an increasing ratio of pension to wages over time (Feldstein \& Liebman, 2002, pp. 2254-2256).

As noted in Brown et al. (2003, p. 4), in the post-war period, for the first time, education occupied one of the central positions in the fuctioning of developed industrial societies, as it was now regarded as a key investment in ensuring economic growth and social justice.

In 1938 , only $8.4 \%$ of children aged between 11 and 18 attended state secondary schools in Great Britain. The ratio increased to $30 \%$ by 1951 and to $37 \%$ in 1968. Higher education also expanded. There were 69,000 students in Great Britain in 1938; by 1963 , there were already 215,000 and this number doubled by 1970. In 1940, only $2.1 \%$ of the national income of England and Wales was spent on education, whereas by 1965 , education expenses grew up to $4.1 \%$ of national income (Brown et al., 2003, p. 5).

During the post-war period, the growth of social spending was not monotonous and regularly became the subject of sharp political struggles. Nevertheless, between 1960 and 2016, social spending increased significantly in developed countries not only in absolute terms but also as a share of GDP (Table 1).

As the welfare state took shape, the division of society into an elite and the masses did not disappear, meaning that the extractive nature of existing institutions remains in place to a certain extent even now. Nevertheless, the dramatic change in the state's role led to a substantial reduction in the costs of eco-

Table 1

Social expenditure in percentage of GDP.

\begin{tabular}{lcc}
\hline Country & 1960 & 2016 \\
\hline France & 14.3 & 32.0 \\
Finland & 9.4 & 29.8 \\
Belgium & 15.9 & 29.2 \\
Sweden & 12.0 & 26.4 \\
Great Britain & 11.2 & 21.2 \\
United States & 6.6 & 18.9 \\
Australia & 8.4 & 17.8 \\
Turkey & $4.0(1980)$ & 12.5 \\
Mexico & $1.7(1980)$ & 7.5 \\
\hline
\end{tabular}

Sources: OECD.Stat (http://stats.oecd.org/Index.aspx?datasetcode=SOCX_AGG, data extracted on 8 January, 2019); Hicks and Misra (1993, Table 2). 
nomic and political competition for the losers, which created preconditions for establishing social peace, further improvement of civic culture and formation of collaborative mechanisms. This was the path of development of the basic institutions for regulating economic competition - the institution of bankruptcy and antitrust legislation (Polterovich, 2015).

In the $18^{\text {th }}$ century, a bankrupt person could be executed and up until the mid$19^{\text {th }}$ century, bankruptcy laws provided for incarceration in Western countries. However, legislation gradually came to take the interests of bona fide debtors into account and to encourage their collaboration with creditors. Legislators provided for voluntary bankruptcy procedures and for signing agreements to make instalment payments on debt in arrears, introducing the mechanism of receivership and the concept of limited liability (Tabb, 1995; Freeman et al., 2006).

Modern bankruptcy laws try to balance interests of debtors, creditors and society, prioritizing public interests. This is why temporarily insolvent firms often receive government support.

Antitrust legislation has evolved in a similar way. The Sherman Act, adopted in the U.S. in 1890, provided for a fine and/or incarceration for up to three years for cartel agreements between firms. The law became more stringent and kept up its "punishing" nature until the last decades of the $20^{\text {th }}$ century, when it became clear that collaboration between enterprises, on the whole, carries more benefit than harm to society. This may have been the result of the improved civic culture of entrepreneurs and the realization of their social responsibility. Nowadays, many types of cartel agreements are allowed, and control over compliance with antitrust legislation is vested with the companies themselves, while the burden of proving that a violation has taken place is laid on the potential plaintiff (Prosvetov and Shastitko, 2005).

In developed countries, monopolistic competition has become quite common, where any firm may retain its market by diversifying its product. A number of modern institutions encourage the "softening" of competition and the expansion of collaboration: public-private partnerships, project financing, tenure in universities and government bodies etc. The institutions of civil society-associations of entrepreneurs and consumers, trade unions - play a prominent role in this respect. These institutions are assuming ever increasing numbers of regulatory and control functions previously performed by the market or by the government (Zudin, 2009).

During the second half of the 1990s, growth in social spending as a percentage of the GDP slowed down in developed countries (Table 2) and even became negative in a number of them. In 2015, the level of inequality in Denmark, Sweden, Austria, France and Germany was higher than in $2003 .{ }^{15}$ These facts

Table 2

Average social spending in percentage of GDP for OECD countries (\%).

\begin{tabular}{lllllllll}
\hline Year & 1980 & 1985 & 1990 & 1995 & 2000 & 2005 & 2010 & 2016 \\
\hline Social spending & 14.9 & 16.5 & 16.9 & 18.8 & 18.0 & 18.8 & 21.1 & 21.0 \\
\hline
\end{tabular}

Source: OECD.Stat (https://stats.oecd.org/Index.aspx?DataSetCode=SOCX_AGG).

${ }^{15}$ https://data.worldbank.org/indicator/SI.POV.GINI 
and the austerity measures, which governments were forced to pursue after the 2007-2008 crisis, provided new momentum for the concepts stating that the era of the welfare state is coming to an end. It should be replaced with a new mechanism for providing social goods, where the institutions of civil society would play the most important role (see references and reviews in McGimpsey, 2017). This view does not contradict our theory. We need, however, additional research to build and assess the scenarios for such a transformation under contemporary conditions.

\subsection{Development of civic culture ${ }^{16}$}

The evolution of morality and civic culture plays a decisive role in developing positive collaboration. The main results of cultural changes in our context are the mitigation of the free rider problem, which is the main obstacle to the efficient operation of collaborative mechanisms and the formation of the collaborativeness, a quality including both the ability to cooperate (cooperativeness) and the aspiration to cooperate with other individuals.

This trend stood out during the second half of the $20^{\text {th }}$ century, although some of its prerequisites arose in moral systems at the dawn of civilization. An important basic moral principle was the so-called "golden rule of morality"; one of its common wordings is: "Do not do unto others what you do not want others to do unto you." In particular, it prescribes honest and faithful behavior towards all people, regardless of the groups they belong to (Guseinov, 1972). This is a declaration of behavioral tolerance and a condemnation of opportunism, which spawns the free rider problem.

An existing norm in a society may be maintained by organized violence, social approval or condemnation or through its interiorization (internalization). Enforcement through violence involves considerable costs, while social approval or condemnation is not always effective. Internalization of the norms of honesty and conscientiousness reduces the cost of collaboration. There are reasons to believe that, in the course of social development, the process of interiorizing norms following from the golden rule, encompasses more and more people and ensures increasingly more consistent compliance with the norms by the individuals. This hypothesis is indirectly confirmed by the negative correlation between the frequency of violation of moral norms and the level of economic development, measured on the per capita GDP (or GNP) basis. Such a correlation is found, in particular, in cross-country comparisons of corruption indices, in experiments to evaluate the frequency of dishonest behavior and in student attitudes towards cheating (for a discussion of this issue and references, see Polterovich, 2017b).

It is well known that the planning horizon widens as wealth grows, thereby increasing the significance of the future (see Strulik, 2012). A reduction in the weighting for short-term benefits in decision-making by individuals helps augment moral standards and reduces the probability of opportunistic behavior.

In a number of works (see, e.g. Das et al., 2008), high correlation is found between the level of interactive tolerance and per capita GDP of a country. This

${ }^{16}$ This section contains a summary and elaboration of some ideas from Polterovich (2017b). 
fact supports the hypothesis that this level rises in the long-run despite the controversial trend over the past 25 years, caused by the intensification of migration processes. Similarly, as per capita GDP rises, there is a tendency towards a higher trust index (Nettle at al., 2011).

The spread of altruism acts as a most powerful factor in decreasing collaboration costs. The inclination towards altruistic behavior also increases as well-being rises (Nettle at al., 2011; Grueter et al., 2016). Possibly, modern altruism - a "descendant" of kinship altruism - is included in the structure of preference of the individual, so that the consumption of other citizens acts as a "good" replaceable with respect to his own consumer goods. Higher individual well-being leads to an increase in his marginal utility of the well-being of others, so that growth in satisfaction depends on the increase in the altruism level.

Today, reputation serves as a vital incentive for altruistic behavior (Wu et al., 2016). The positive assessment of altruists is characteristic of world religions and is an essential trait in contemporary morals, inciting individuals to collaboration. At a time when it became the most effective coordination mechanism, a positive cycle appeared: altruism-collaboration-economic growth-altruism.

A similar reputation mechanism is also applicable to firms, encouraging them to behave altruistically. One of the results was a recognition of corporate social responsibility, of the idea that corporate leaders are responsible for the impact their corporations have on society and the environment (D'Amato et al., 2009). The acknowledgement of social responsibility stimulates the incorporation of mechanisms of collaboration with consumers and other firms into the mechanism of competition.

The most important trend in the development of civic culture, contributing to the expansion of collaboration in relations between countries, is presumably the spread of cosmopolitanism (Delanty, 2014).

These tendencies are long-term in nature; within relatively short timeframes, a reverse effect is possible in some countries and even in the majority of developed countries. Such short-term effect is observed partly as a result of intensive migration and is likely to become stronger as a result of the current confrontation between the U.S. and its European partners. However, historic experience suggests that, upon the completion of the current crisis, the improvement in civic culture will continue, contributing to the development of collaborative mechanisms.

\subsection{On the role of geographic factors}

We discussed above the factors and development mechanisms that are common for all developed countries. We did not consider geographic factors that affected the differences between them and, even to a greater extent, the differences between the West and the rest of the world. At the dawn of human civilization, as Diamond convincingly showed, geography was one of the most important determinants of the continental development. In addition, the need for irrigation systems had a substantial impact on the formation and structure of ancient civilizations.

According to K. Wittfogel's widely known theory of the hydraulic state, irrigation farming, which played a decisive role in the economies of countries with hot 
climates and scarce water resources, became the basis for the emergence of power hierarchies. Constructing complex irrigation structures required the coordination of large masses of people and, therefore, centralization. At the same time, centralized ownership of irrigation infrastructure provided the monarch with unlimited power over the population. Hence, according to Wittfogel, the despotic nature of these ancient states came into being; examples include China, Egypt, India etc. (Wittfogel, 1957).

Wittfogel's theory became the starting point for many studies dedicated to the role of geographic factors in the emergence of the state (see reviews in Galeev, 2011; Bichsel, 2016). A number of critics of this theory emphasized the lack of synchronization between the formation of centralized governmental structures and irrigation systems. It was found that sufficiently complex ancient irrigation systems appeared without the involvement of the state (see, e.g. Stride et al., 2009, dealing with the irrigation system in the suburbs of Samarkand). Thus, there is no hard connection between the construction of complex irrigation structures and the formation of despotic regimes.

To explain these observations, M. Midlarsky proposed accounting for the second geographic factor (in addition to precipitation) — the length of the state's water borders. The greater their share is, the lower the threat of foreign invasion and, consequently, the lower the need for strong centralization. This hypothesis was confirmed, based on a sample of 91 countries between 1973 and 1987; in respective regressions, both factors have a significant and positive effect on the index of political rights (Midlarsky, 1995).

It should be noted that the states that practised irrigation farming had an important advantage in preventing foreign invasions: they had qualified builders of fortification at their disposal. Wittfogel pointed out this circumstance.

The impact of geographic factors on modern production is confirmed by numerous studies (see review in Carleton and Hsiang, 2016). In particular, in Burke et al. (2015), the optimal level of annual average temperature was found: $13^{\circ} \mathrm{C}$. An excess of this level under fixed control variables leads to a sharp decline in production. Both high annual average temperature and low precipitation are statistically linked to increased levels of interpersonal and intergroup violence (Carleton and Hsiang, 2016) which, obviously, hinders the development of positive collaboration mechanisms.

It should be noted that a consensual form of democracy and a corporatist governance system are characteristic of Northern and Central Europe (Lijphart, 2012), where the average annual temperature is below the optimal level. The question is whether these institutional features are related to geographic factors. It is quite probable that relatively severe natural conditions stimulate successful countries to form collaborative institutions more rapidly.

\subsection{Sunset or sunrise?}

Both the authors of the institutional theories reviewed in the first part of this paper and Welzel, the author of the culture-centric theory, consider modern Western democracy as the pinnacle of social development and do not even attempt to answer the question regarding its future prospects. Addressing this problem requires identification of internal development mechanisms. 
Fukuyama raised this question in his monograph (2014) and his answer is part of the title: the sunset (decay) is ahead. The arguments are based on an analysis of the U.S. governance system. Fukuyama sees the main reason for the looming decline of the United States in the inefficient decision-making system which, in his opinion, contains too many veto players. The president, two chambers of parliament, the federal and state governments, the court - each of these institutions can impede a policy choice or a reform.

The U.S., in Fukuyama's opinion, finds itself in a trap, in a "bad equilibrium." Traditionally distrusting the government, citizens, on the one hand, try to limit its power, and, on the other hand, they refuse to pay higher taxes. As a result, the government works inefficiently, fueling citizen distrust towards it. Thus, distrust towards the government becomes a "self-fulfilling prophecy."

Two circumstances prevent the exit from this trap. First, the situation described is beneficial for a number of political players. Second, the traditional U.S. way to improve its political system is to ensure higher transparency and to provide greater controlling rights to the voter. However, nearly all such reforms fail, as "democratic publics are not in fact able by background or temperament to make large numbers of complex public policy choices; what has filled the void are wellorganized groups of activists who are unrepresentative of the public as a whole. The obvious solution to this problem would be to roll back some of the would-be democratizing reforms, but no one dares suggest that what the country needs is a bit less participation and transparency" (Fukuyama, 2014, p. 482).

This analysis does not seem convincing to me. The presence of a large number of veto players in the U.S. political system makes it close to some extent-as follows from Fukuyama's remarks - to consensual European systems, which, as Lijphart (inventor of the term) has demonstrated, are more efficient than majoritarian democracies. However, a typical example of a majoritarian democracy is Great Britain, which Fukuyama deems to be an example of efficiency and contrasts it and the U.S. system. Fukuyama's argument against consensus-based systems is that they are more costly.

Here, it seems to me, Fukuyama, following some other authors cited above, underestimates the role of culture. It is civic culture, the ability to collaborate and reach compromises that determine the costs in question. Lijphart's results suggest that, in this respect, the consensus democracies are ahead of the U.S. This conclusion is partly confirmed by ranking countries according to the human capital index: Norway, Switzerland, Germany, Denmark and the Netherlands rank higher, while Sweden is only slightly behind the U.S. but ahead of Great Britain. ${ }^{17}$ Moreover, consensus democracies are based on representation, which, to a certain extent, prevents the dependency of political decisions on the opinion of voters who lack the requisite knowledge. Thus, the decay mentioned by Fukuyama is characteristic only of those social systems which failed to find an efficient balance between culture and institutions. ${ }^{18}$

Considering the evolution of the state, Fukuyama does not pay sufficient attention to its two turning points: formation of the ideology of technical and social

\footnotetext{
${ }^{17}$ See https://en.wikipedia.org/wiki/List_of_countries_by_Human_Development_Index

${ }^{18}$ It should be noted that, in a number of discussions, Fukuyama considers Denmark which is a typical example of consensus democracies, as a pattern of an efficient political system.
} 
progress and the emergence of the welfare state concept. ${ }^{19}$ Both of these factors determined the crucial changes in both socioeconomic policy and in institutions, which occurred in the $20^{\text {th }}$ century, especially during its second half. They built a foundation for gradual replacement of the institutions of competition and power with institutions of collaboration.

\subsection{Conclusion: towards the welfare world}

The proposed concept of socioeconomic development - the philosophy of collaboration-differs substantially from the four general theories discussed above in two aspects. First, it takes into account the links between the four factors - culture, institutions, technical progress and the level of well-being and recognizes the importance of natural conditions. This makes it possible to describe the mechanisms of evolution, transitions between development stages, in more detail. On the whole, this approach is natural and quite consistent with the spirit of numerous specific studies. One should appreciate the courage of the authors, who attempted to narrow down the number of explanatory development factors as much as possible. If it succeeded, we would obtain a far simpler apparatus for further work.

Second, by focusing on the evolution of coordination mechanisms, we describe the development process in new, more differentiated terms. The growth of inclusivity, as well as the "openness of access," is possible due to two different processes - expanding competition or increasing the collaboration radius. Vagueness, the ambiguity of basic concepts, which is characteristic of purely institutional theories, puts a tight constraint on the potential to obtain convincing answers to fundamental questions.

I hope that the new approach has enabled a fuller view of the structure of socioeconomic evolution and thus identified probable paths for further development. Instead of the "end of history" allegedly brought about as a result of the domination of inclusive institutions or open access orders, the proposed theory predicts a lengthy process of reducing transaction costs generated by the mechanisms of competition and power, due to the increasing role of collaborative mechanisms; this tendency results from the development of civic culture and the improvement of well-being, in turn caused by technical and organizational innovations. It appears quite probable that a change in mass culture, greater tolerance and altruism and the spread of cosmopolitanism will lead to further development of mechanisms for international collaboration and the creation of institutions capable of ensuring the welfare world.

The impoverishment of the proletariat in Marx's time, accompanied by waves of violence, nearly made his prophecies come true. Capitalism endured since the elite realized the need to give up part of their privileges for the sake of their own well-being. Today, when the conflict escalation between "golden billion" and developing countries threatens the existence of humankind, developed

\footnotetext{
${ }^{19}$ Fukuyama specifies two driving forces of modernization: military competition and social mobilization, brought about by industrialization. He stressed the importance of the second factor in the development of democracy, noting that economic growth encouraged the appearance of new social groups ready for collective actions to achieve participation in the political system (Fukuyama, 2014, pp. 26-27).
} 
countries should address the task of reducing intercountry income inequality as the basis for their foreign policy. The relevant institutions have already been partially created.

Following World War II, the elite of the developed countries began to form institutions aimed at preventing both domestic and international conflicts. It was recognized that, first of all, the world needs a system of international aid to countries affected by natural disasters, epidemics, drought and wars. To solve this task, the OECD set up the Development Assistance Committee in 1961 (DAC). In 1970, the UN General Assembly passed a resolution that each developed country should gradually increase its amount of aid to developing countries, so that by 1975 it would reach $0.7 \%$ of its gross national product (see Qian, 2015). Since then, the amount of aid has grown due both to government spending and to private foundations and money transfers, while the second component increased significantly faster. In 1992, each flow was equal to approximately USD 100 billion, while in 2014, the first component was 147 billion and the second was 801 billion, 5.4 times larger (Hudson Institute, 2016, Fig. 1). Nevertheless, the resolution of a pretty small task set by the UN is still far away: the official aid from 28 countries which were DAC members in 2014 , was only $0.3 \%$ of their total gross national income. Only five countries - Sweden, Luxembourg, Norway, Denmark and Great Britain - reached the threshold of $0.7 \%$ (Hudson Institute, 2016, Fig. 2).

Researchers diverge in their assessment of the efficiency of this aid. There are two reasons for doubts. First of all, local officials are unable to dispose of the aid correctly and, moreover, they appropriate it; intensifying the rent-seeking process, international aid degrades the governance system. Second, foreign aid is often determined by the goals of donor countries, rather than the needs of recipient countries (Qian, 2015).

The last remark relates also to another type of international aid - the provision of loans and consulting services to developing countries. This was mentioned by J. Stiglitz: "There is ... a broad consensus that the international economic institutions have created unfair rules of the game ... and have foisted failed policies on developing countries that are dependent on these institutions and on donors for assistance" (Stiglitz, 2008, p. 53).

Nevertheless, a number of studies show that international aid stimulates economic growth in developing countries. In particular, Galiani et al. (2014) emphasize the importance of physical investments. In Arndt et al. (2016), the authors state that, in the long run, investments in human capital also have a beneficial effect.

Unfortunately, the current international situation does not allow us to hope for a rapid increase in aid from the Western countries to the rest of the world. However, sooner or later, it will be realized that this policy has no alternative. Short-run state egoism must give way to the strategy of creating the welfare world since, only by aligning the levels of development of different countries, we can hope to expand collaboration between them to resolve issues that face the global community. One of those issues is the preservation of the environment. The geographic factor which played such an important role at the initial development stage of human communities, once again is coming to the foreground, fostering the formation of global collaboration institutions. 


\section{Acknowledgements}

The first part of the article was prepared with the financial support of the Russian Foundation for Basic Research (Project No. 17-02-00524a).

\section{References}

Acemoglu, D. \& Robinson, J. (2012). Why nations fail: The origins of power, prosperity, and poverty. New York: Crown.

Acemoglu, D., \& Robinson, J. A. (2016). Paths to inclusive political institutions. In J. Eloranta, E. Golson, A. Markevich, \& N. Wolf (Eds.), Economic history of warfare and state formation (pp. 3-50). London: Springer (see also: https://economics.mit.edu/files/11338).

Alesina, A., \& Giuliano, P. (2015). Culture and institutions. Journal of Economic Literature, 53 (4), 898-944. https://doi.org/10.1257/jel.53.4.898

Arndt, C., Jones, S., \& Tarp, F. (2016). What is the aggregate economic rate of return to foreign aid? The World Bank Economic Review, 30 (3), 446-474. https://doi.org/10.1093/wber/lhv033

Arslanov, V. V. (2016). Geography, institutions and the roots of global inequality: A critical appraisal of Acemoglu and Robinson's theory of economic development. Moscow: IE RAS (in Russian).

Balatsky, E. V. (2017). The concept of inclusive institutions and its applications. Obshchestvennye Nauki i Sovremennost, 2, 143-156 (in Russian).

Balatsky, E. V., \& Pliskevich, N. M. (2017). Economic growth in the context of extractive institutions: The Soviet paradox and current events. Mir Rossii, 4, 97-117 (in Russian).

Bichsel, C. (2016). Water and the (infra-) structure of political rule: A synthesis. Water Alternatives, 9 (2), 356-372. http://www.water-alternatives.org/index.php/alldoc/articles/vol9/ v9issue2/320-a9-2-10/file

Birch, J., \& Okasha, S. (2015). Kin selection and its critics. BioScience, 65 (1), 22-32. https:// doi.org/10.1093/biosci/biu196

Briggs, A. (1961). The welfare state in historical perspective. European Journal of Sociology, 2 (2), 221-258. https://doi.org/10.1017/S0003975600000412

Brown, Ph., Halsey, A. H., Lauder, H., \& Wells, A. S. (2003). The transformation of education and society: An introduction. In Ph. Brown, A. H. Halsey, H. Lauder, \& A. S. Wells (Eds.), Education, culture, economy and society (pp. 1-44). New York: Oxford University Press.

Bunch, B., \& Hellemans, A. (2004). The history of science and technology. Boston and New York: Houghton Mifflin Company.

Burke, M., Hsiang, S. M., \& Miguel, E. (2015). Global non-linear effect of temperature on economic production. Nature, 527, 235-239. https://doi.org/10.1038/nature15725

Carleton, T. A., \& Hsiang, S. M. (2016). Social and economic impacts of climate. Science, 353 (6304), aad9837. https://doi.org/10.1126/science.aad9837

Carneiro, R. L. (2002). Was the chiefdom a congelation of ideas? Social Evolution and History, $1(1), 80-100$.

Chang, H.-J. (2003). Kicking away the ladder: Development strategies in historical perspective. London: Anthem Press.

Chubaryan, A. O., \& Mirzehanov, V. S. (Eds.) (2014). The world history (in 6 vols.). Vol. 5: The world in the XIX century: On the way to industrial civilization. Moscow: Nauka (in Russian).

D'Amato, A., Henderson, S., Florence, S. (2009). Corporate social responsibility and sustainable business. A guide to leadership tasks and functions. Center for Creative Leadership. Greensboro, North Carolina: CCL Press.

Das, J., DiRienzo, C., \& Tiemann, Th. (2008). A global tolerance index. Competitiveness Review: An International Business Journal, 18 (3), 192-205. https://doi.org/10.1108/10595420810905975

Delanty, G. (2014). The prospects of cosmopolitanism and the possibility of global justice. Journal of Sociology, 50 (2), 213-228. https://doi.org/10.1177\%2F1440783313508478

Diamond, J. (1997). Guns, germs, and steel: The fate of human societies. New York: W.W. Norton. 
Diamond, J. (2012a). What makes countries rich or poor? New York Review of Books, June 7.

Diamond, J. (2012b). Reply to the letter to the editors by Daron Acemoglu and James A. Robinson. New York Review of Books, August 16.

Feldstein, M., \& Liebman, J. B. (2002). Social security. In A. J. Auerbach, \& M. Feldstein (Eds.), Handbook of public economics (vol. 4, pp. 2245-2324). Amsterdam: Elsevier Science. https:// doi.org/10.1016/S1573-4420(02)80011-8

Freeman, M., Pearson, R., \& Taylor, J. (2006). The limitation of liability in British joint-stock companies, 1720-1844. Paper presented at the XIV International Economic History Congress, Helsinki, 21-25 August. http:/www.helsinki.fi/iehc2006/papers2/Pearson.pdf

Fukuyama, F. (2011). The origins of political order: From prehuman times to the French revolution. London: Profile Books.

Fukuyama, F. (2012). Acemoglu and Robinson on why nations fail. The American Interest, March 26. https://www.the-american-interest.com/2012/03/26/acemoglu-and-robinson-onwhy-nations-fail/

Fukuyama, F. (2014). Political order and political decay: From the industrial revolution to the globalization of democracy. New York: Farrar, Straus and Giroux.

Gabor, A. (2005). Guns for the sultan: Military power and the weapons industry in the Ottoman Empire. Cambridge: Cambridge University Press.

Galeev, S. V. (2011). K. Wittfogel's hydraulic state theory and its modern critique. Sotsiologicheskoe Obozrenie, 10 (3), 155-179 (in Russian)

Galiani, S., Knack, S., Xu, L. C., \& Zou B. (2014). The effect of aid on growth: Evidence from a quasi-experiment. World Bank Policy Research Working Paper, No. 6865.

Grueter, C. C., Ingram, J. A., Lewisson, J. W., Bradford, O. R., Taba, M., Coetzee, R. E., \& Sherwood M. A. (2016). Human altruistic tendencies vary with both the costliness of selfless acts and socioeconomic status. Peer J, 4, e2610. https://dx.doi.org/10.7717/peerj.2610

Guseinov, A. A. (1972). The golden rule of morality. Vestnik MGU. Seria Philosophia, 4, 53-63 (in Russian).

Hicks, A., \& Misra, J. (1993). Political resources and the growth of welfare in affluent capitalist democracies, 1960-1982. American Journal of Sociology, 99 (3), 668-710. https://doi.org/ $10.1086 / 230320$

Hudson Institute (2016). The index of global philanthropy and remittances 2016. Washington, DC.

Kirdina, S. G. (2016). Institutions and geography in economic development: A heterodox economic discussion. Prostranstvennaya Ekonomika, 3, 133-150 (in Russian). https://dx.doi.org/10.14530/ se.2016.3.133-150

Kulisher, I. M. (1922). Lectures on the history of economic life in Western Europe (Part II). Petrograd: Tsentralnoye Kooperativnoye Izdatelstvo "Mysl" (in Russian).

Levy,J.S.,\&Thompson,W.R.(2011). The arcofwar: Origins, escalation, andtransformation.Chicago: University of Chicago Press. https://doi.org/10.7208/chicago/9780226476278.001.0001

Lijphart, A. (2012). Patterns of democracy. Government forms and performance in thirty-six countries $\left(2^{\text {nd }}\right.$ ed.). New Haven: Yale University Press.

Masse, P. (1965). The French plan and economic theory. Econometrica, 33 (2), 285-294. https:// doi.org/10.2307/1909789

McGimpsey, I. (2017). Late neoliberalism: Delineating a policy regime. Critical Social Policy, 37 (1), 64-84. https://doi.org/10.1177/0261018316653552

Midlarsky, M. I. (1995). Environmental influences on democracy. Aridity, warfare and a reversal of the causality arrow. Journal of Conflict Resolution, 39 (2), 224-262. https://doi. org/10.1177/0022002795039002002

Mokyr, J. (2005). The great synergy: The European Enlightenment as a factor in modern economic growth. Unpublished manuscript, Northwestern University. https://pdfs.semanticscholar.org/cff 8/3056fab568f5085024a918df813a7661a28a.pdf (published in: W. Dolfsma, \& L. Soete (Eds.) (2006). Understanding the dynamics of a knowledge economy (pp. 7-41). Cheltenham, UK: Edward Elgar).

Mokyr, J. (2016). A culture of growth: The origins of the modern economy. Presidential Address, Atlantic Economic Association, Lisbon, March. https://doi.org/10.2307/j.ctt1wf4dft 
Natkhov, T. V., \& Polishchuk, L. I. (2017a). Political economy of institutions and development: The importance of being inclusive. Reflections on "Why Nations Fail" by D. Acemoglu and J. Robinson. Part I: Institutions and economic development. Institutional choice. Journal of the New Economic Association, 2 (34), 12-38 (in Russian). https://doi.org/10.31737/22212264-2017-34-2-1

Natkhov, T. V., \& Polishchuk, L. I. (2017b). Political economy of institutions and development: The importance of being inclusive. Reflections on "Why Nations Fail" by D. Acemoglu and J. Robinson. Part II. Institutional change and implications for Russia. Journal of the New Economic Association, 3 (35), 12-32 (in Russian). https://doi.org/10.31737/2221-2264-201735-3-1

Nepomnin, O. E. (2005). History of China: The era of Qing. XVII-the beginning of XX century. Moscow: Vostochnaya Literatura (in Russian).

Nettle, D., Colléony, A., \& Cockerill, M. (2011). Variation in cooperative behaviour within a single city. PLoS ONE, 6 (10), e26922. https://doi.org/10.1371/journal.pone.0026922

North, D. (1990). Institutions, institutional change and economic performance. New York: Norton. https://doi.org/10.1017/CBO9780511808678

North, D., Wallis, J., \& Weingast B. (2009). Violence and social orders. A conceptual framework for interpreting recorded human history. Cambridge: Cambridge University Press. https://doi. org/10.1017/CBO9780511575839

North, D. C., Wallis, J. J., Webb, S. B., \& Weingast, B. R. (2013). In the shadow of violence: A new perspective on development. Unpublished manuscript. https://web.stanford.edu/group/ mcnollgast/cgi-bin/wordpress/wp-content/uploads/2013/10/LAO_CUP_Conclusion.printversion.15.0829.pdf

Ober, J. (2015). The rise and fall of classical Greece. New York: Penguin. https://doi. org/10.1515/9781400865550

Ogilvie, Sh. (2014). The economics of guilds. Journal of Economic Perspectives, 28 (4), 169-192. https://dx.doi.org/10.1257/jep.28.4.169

Polterovich, V. M. (2007). Elements of the theory of reforms. Moscow: Ekonomika (in Russian).

Polterovich, V. M. (2014). Why reforms fail. Journal of the New Economic Association, 3 (23), 169-173 (in Russian).

Polterovich, V. M. (2015). From social liberalism towards the philosophy of collaboration. Obshchestvennye Nauki i Sovremennost, 4, 41-64 (in Russian).

Polterovich, V. M. (2016a). Institutional reforms and civic culture. Istoricheskaya i Sotsialnoobrasovatelnaya Mysl, 8 (2-2), 225-238 (in Russian).

Polterovich V. M. (2016b). Institutions of catching-up development (On the project of a new model for economic development of Russia). Economic and Social Changes: Facts, Trends, Forecasts, 5 (47), 34-56 (in Russian).

Polterovich, V. M. (2017a). Designing the strategies for socio-economic development: Science vs. ideology. Journal of the New Economic Association, 3 (35), 198-206 (in Russian). https://doi. org/10.31737/2221-2264-2017-35-3-12

Polterovich, V. (2017b). Positive collaboration: Factors and mechanisms of evolution. Russian Journal of Economics, 3 (1), 24-41. https://doi.org/10.1016/j.ruje.2017.02.002

Polterovich, V. (2017c). Tolerance, collaboration, and economic growth. Voprosy Ekonomiki, 11, 33-49 (in Russian). https://doi.org/10.32609/0042-8736-2017-11-33-49

Polterovich, V. M. (2017d). Towards a general theory of social and economical development. In C. Welzel, Freedom rising (pp. 6-14). Moscow: VTsIOM (in Russian).

Prosvetov, V., \& Shastitko, A. (2005). Analysis of the antimonopoly legislation in force in the Russian Federation and comparisons with modern EU law, Possible ways to increase the effectiveness of its application in Russia. Analysis of antitrust legislation and law enforcement in the EU. Moscow: RECEP (in Russian).

Qian N. (2015). Making progress on foreign aid. Annual Review of Economics, 7 (1), 277-308. https://doi.org/10.1146/annurev-economics-080614-115553

Rhodes, P. (1998). Athenian democracy. In Antiquity and the middle ages of Europe (pp. 40-52). Perm: Permskiy Universitet (in Russian). 
Stiglitz, J. E. (2008). Is there a Post-Washington consensus? In N. Serra, \& J. E. Stiglitz (Eds.), The Washington Consensus reconsidered: Towards a new global governance (pp. 41-56). Oxford: Oxford University Press. https://doi.org/10.1093/acprof:oso/9780199534081.003.0004

Stride, S., Rondelli, B., \& Mantellini, S. (2009). Canals versus horses: Political power in the oasis of Samarkand. World Archaeology, 41 (1), 73-87. https://doi.org/10.1080/00438240802655302

Strulik, H. (2012). Patience and prosperity. Journal of Economic Theory, 147 (1), 336-352. https:// doi.org/10.1016/j.jet.2011.10.008.

Tabb, C. J. (1995). The history of the bankruptcy laws in the United States. American Bankruptcy Institute Law Review, 3 (5), 5-51.

Thies, C. G. (2012). War and the Middle Eastern state. Paper prepared for the IPSA World Congress, Madrid, Spain, July 8-12. http://paperroom.ipsa.org/papers/paper_9578.pdf

Volkov, S. V. (2017). Elite groups of traditional societies. Moscow: Russkiy Fond Sodeistviya Obrazovaniyu i Nauke (in Russian).

Welzel, C. (2013). Freedom rising: Human empowerment and the quest for emancipation. Cambridge, UK: Cambridge University Press. https://doi.org/10.1017/CBO9781139540919

Westin, R. A. (2014). The historical origins of progressive taxation. The Journal Jurisprudence, 23, 203-241. http://www.jurisprudence.com.au/wp-content/uploads/2018/07/westin.pdf

Wittfogel, K. A. (1957). Oriental despotism: A comparative study of total power. New Haven and London: Yale University Press.

Wu, J., Balliet, D., \& Van Lange, P. A. M. (2016). Reputation, gossip, and human cooperation. Social and Personality Psychology Compass, 10 (6), 350-364. https://doi.org/10.1111/spc3.12255

Zaostrovtsev, A.P. (2013). Douglas North: The escape from the neoclassical mainstream. Obshchestvennye Nauki i Sovremennost, 4, 140-150 (in Russian).

Zaostrovtsev, A. P. (2014). History by Acemoglu-Robinson: Institutions, development, and the limits of authoritarian growth. Obshchestvennye Nauki i Sovremennost, 3, 32-43 (in Russian).

Zudin, A. Yu. (2009). Associations-business-state. Classic and modern norms of relations in the Western countries (Preprint WP1/2009/053). Moscow: SU-HSE (in Russian). 